Article

\title{
Thermo-Economic Evaluation of Organic Rankine Cycles for Geothermal Power Generation Using Zeotropic Mixtures
}

\author{
Florian Heberle * and Dieter Brüggemann \\ Center of Energy Technology (ZET), University of Bayreuth, Universitätsstraße 30, 95447 Bayreuth, \\ Germany; E-Mail: zet@uni-bayreuth.de \\ * Author to whom correspondence should be addressed; E-Mail: florian.heberle@uni-bayreuth.de; \\ Tel.: +49-921-55-7163; Fax: +49-921-55-7165.
}

Academic Editor: Roberto Capata

Received: 30 January 2015 / Accepted: 11 March 2015 / Published: 17 March 2015

\begin{abstract}
We present a thermo-economic evaluation of binary power plants based on the Organic Rankine Cycle (ORC) for geothermal power generation. The focus of this study is to analyse if an efficiency increase by using zeotropic mixtures as working fluid overcompensates additional requirements regarding the major power plant components. The optimization approach is compared to systems with pure media. Based on process simulations, heat exchange equipment is designed and cost estimations are performed. For heat source temperatures between 100 and $180{ }^{\circ} \mathrm{C}$ selected zeotropic mixtures lead to an increase in second law efficiency of up to $20.6 \%$ compared to pure fluids. Especially for temperatures about $160{ }^{\circ} \mathrm{C}$, mixtures like propane/isobutane, isobutane/isopentane, or R227ea/R245fa show lower electricity generation costs compared to the most efficient pure fluid. In case of a geothermal fluid temperature of $120^{\circ} \mathrm{C}, \mathrm{R} 227 \mathrm{ea}$ and propane/isobutane are cost-efficient working fluids. The uncertainties regarding fluid properties of zeotropic mixtures, mainly affect the heat exchange surface. However, the influence on the determined economic parameter is marginal. In general, zeotropic mixtures are a promising approach to improve the economics of geothermal ORC systems. Additionally, the use of mixtures increases the spectrum of potential working fluids, which is important in context of present and future legal requirements considering fluorinated refrigerants.
\end{abstract}

Keywords: Organic Rankine Cycle; ORC; zeotropic mixtures; thermo-economic analysis; geothermal power generation 


\section{Introduction}

For the purpose of geothermal power generation utilizing low-temperature resources, binary power plants are reasonable under thermodynamic and economic aspects [1,2]. In this context, the Organic Rankine Cycle (ORC) is mainly applied as energy conversion system. Regarding the optimisation of the subcritical ORC, a selection of pure media as working fluids is performed by numerous authors in respect to the heat source characteristics [3-8]. A promising optimisation approach for ORC systems is the use of mixtures as working fluids. Due to a non-isothermal phase change zeotropic mixtures lead to a better match of the temperature profiles of the ORC and the heat source or heat sink at evaporation and condensation. Angelino and Colonna di Paliano [9] show this adaption of the ORC to a sensible heat sink by analyzing mixtures of linear siloxanes and natural hydrocarbons. For a case study concerning waste heat recovery, the same authors determine fan power savings of an air-cooling system by $49 \%$ using an equimolar mixture of $n$-butane and $n$-hexane as working fluid [10]. However, an additional heat transfer surface is required. In the context of geothermal applications, several case studies are performed for zeotropic mixtures as ORC working fluids considering subcritical and transcritical cycles [11-13]. More comprehensive analyses including sensitivity for crucial parameters, like mixture composition, heat source temperature or temperature difference of the cooling media are recently performed [14-30]. In general, results confirm the potential for an increase in efficiency of ORC systems by the use of zeotropic mixtures as working fluids. Mainly, the reduction of irreversibilities in the condenser due to a match of the temperature profiles is highlighted.

For low-temperature heat sources Andreasen et al. [28] considered pure components and their zeotropic mixtures as working fluids for subcritical and transcritical cycles. In case of $120{ }^{\circ} \mathrm{C}$ heat source temperature, mixtures of propane and higher boiling natural hydrocarbons as well as isobutane/isopentane show high first law efficiencies for subcritical cycles. Among the considered pure fluids R227ea is suitable. In general, the heat exchange capacity for the condenser increases for the investigated mixtures, which is an indicator for additional required heat transfer surface. Lecompte et al. [29] perform a second law analysis for heat source temperatures between 120 and $160{ }^{\circ} \mathrm{C}$. Subcritical ORCs are investigated for eight zeotropic mixtures and their pure components. For a heat source temperature of $150{ }^{\circ} \mathrm{C}$, isobutane/isopentane with mole concentrations of $0.81 / 0.19$ leads to an increase in efficiency of $7.1 \%$ compared to the most efficient pure component. In this case, the resulting temperature glide at condensation lead to a good match of the temperature profiles in the condenser. Dong et al. [30] describe this fundamental relation in the same way for a high-temperature heat source and siloxane mixtures. Also, the reduction of irreversibilities in the condenser affects the efficiency more than the one in the evaporator. The mentioned investigations of ORC systems using zeotropic mixtures as working fluids were conducted with the focus on the optimization of first or second law efficiency. Studies including the evaluation of heat transfer requirements and consequently economic parameters have not been published yet. However, Weith et al. [31] recently show for a waste heat recovery application of the ORC that the use of a siloxane mixture leads to an efficiency increase of 3\% compared to the most efficient pure component. This performance improvement is accompanied by a $14 \%$ higher heat transfer surface of the evaporator.

Existing thermo-economic analysis related to ORC power systems focus on fluid selection concerning pure working fluids and power plant configurations, like combined heat and power generation or other 
complex systems [32-43]. Regarding ORC power plants for waste heat recovery with an electric capacity below $5 \mathrm{~kW}$, Quoilin et al. [39] determine specific investment costs for 8 working fluids in the range of $2,136 € / \mathrm{kW}$ and $4,260 € / \mathrm{kW}$. For the same thermal energy source Imran et al. [40] considered different plant schemes and working fluids for a thermo-economic analysis. The electric power output ranges between 30 and $120 \mathrm{~kW}$. The authors present specific investment costs in the range of 3,556 and 4,960€/kW. In case of a $20 \mathrm{MW}$ geothermal power plant Quoilin et al. [41] indicate specific investment costs of about $1,750 € / \mathrm{kW}$ for the ORC module and $3,000 € / \mathrm{kW}$ for the total ORC system including for example engineering or buildings. Astolfi et al. [42] perform a thermo-economic analysis for geothermal ORC at selected temperatures of the heat source, considering different cycle schemes and pure fluids. The most efficient concepts for $120^{\circ} \mathrm{C}$ lead to specific investment costs of the ORC power plant of $3,750 € / \mathrm{kW}$. In case of geothermal fluid temperature of $150{ }^{\circ} \mathrm{C}$ minimal specific investment costs of $2,500 € / \mathrm{kW}$ result. Tempesti and Fiaschi [43] investigate a hybrid ORC power plant using geothermal and solar energy for three pure working fluids. In this context, R245fa leads to the lowest electricity generation costs between 93 and $120 € / \mathrm{MWh}$ depending on design month.

In contrast to previous studies, we provide a thermo-economic analysis of geothermal ORCs under consideration of zeotropic mixtures as potential working fluids. A comparison to pure working fluids is performed to clarify, if the efficiency increase overcompensates the additionally required heat transfer surface. First, a selection of potential mixture components based on thermodynamic properties is carried out. For the considered zeotropic mixtures the reliability of fluid properties is discussed. By varying mixture concentration and heat source temperature, efficient pure working fluids and fluid mixtures are identified according to second law of thermodynamics. For the most efficient working fluids, required heat exchange equipment is designed according to guidelines of the VDI Heat Atlas [44]. The resulting heat transfer surfaces and power capacities of the rotating equipment, here turbine and pump, are used as input data for cost estimations. An evaluation of the considered working fluids is conducted by specific investment costs and electricity generation costs for selected power plant concepts.

\section{Methodology}

The presented thermo-economic analysis is divided into the following subsections: reliability of fluid properties, second law analysis, heat exchanger design, cost estimation and economic parameters.

\subsection{Reliability of Fluid Properties}

The fluid properties of pure fluids and fluid mixtures are calculated by the REFPROP database Version 8.0 [45]. The reliability of fluid properties is discussed comparing experimental data from literature and theoretical data for vapour-liquid equilibrium (VLE) calculated by REFPROP. In addition, selected properties like liquid and gaseous density or heat capacity are compared to experimental data.

\subsection{Process Simulation and Second Law Analysis}

For steady-state simulations the software Cycle Tempo [46] is used. The schematic scheme of the power plant is shown in Figure 1a. The liquid working fluid is forced to a higher pressure level by the 
pump. The heat input of the geothermal resource is realized in two steps by a preheater and an evaporator. The saturated vapour is expanded in a turbine. Finally, the working fluid is condensed in the condenser. For dry fluids, which show a positive gradient $d T / \mathrm{d} s$ of the dew line in the $T, s$-diagram, an internal heat exchanger is considered. The changes of state in case of isopentane as working fluid are plotted in Figure 1b exemplarily.

(a)

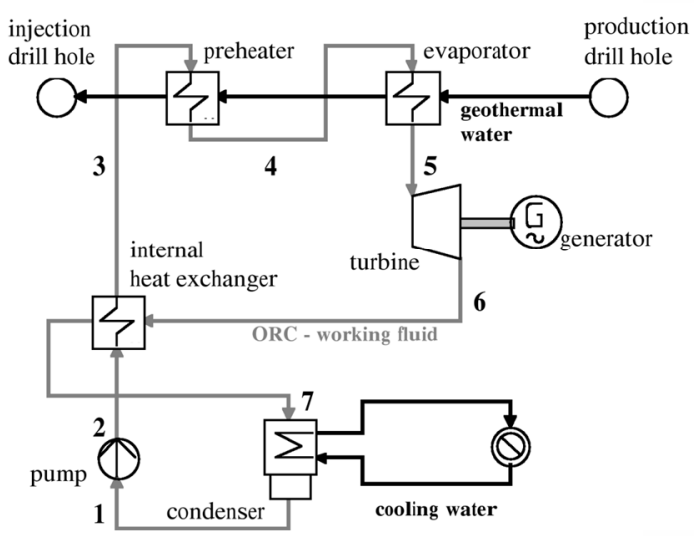

(b)

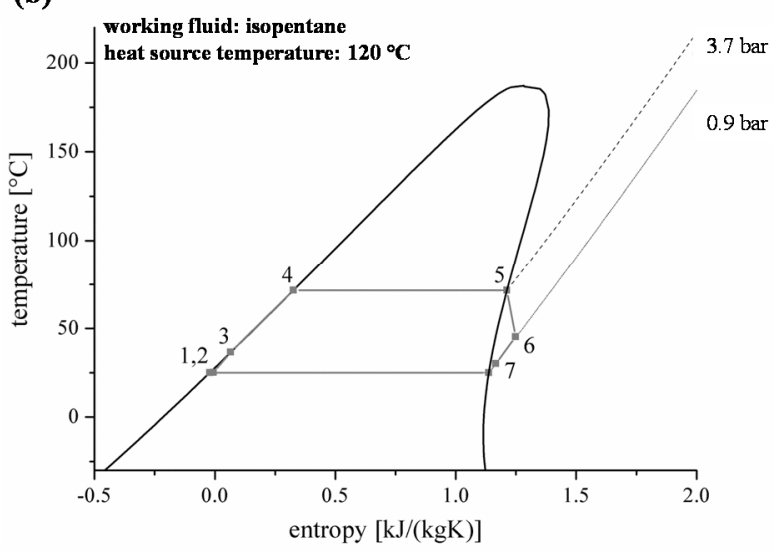

Figure 1. (a) Scheme of the geothermal ORC power plant; (b) Corresponding $T, s$-diagram for the ORC using the working fluid isopentane.

We performed process simulations for subcritical cycles in order to maximise the electrical power output and second law efficiency of the ORC. For the calculations, the minimal temperature difference $\Delta T_{\mathrm{PP}}$ in the heat exchangers is assumed to be constant. In this context, the process pressures of the ORC are adapted by user subroutines. The reinjection temperature of the geothermal fluid is chosen as an independent design variable to obtain the maximum power output of the system. Therefore, the Cycle Tempo internal optimization routine is used. A relative accuracy for convergence of $1.0 \cdot 10^{-4}$ is considered. The plant performance is evaluated neglecting pressure and heat losses in the pipes and components. Fluid properties of water are considered for the geothermal fluid. For the sensitivity analysis, the mixture composition is varied in discrete steps of $10 \mathrm{~mol} \%$. Additional boundary conditions are listed in Table 1. The mass flow rate of the brine of $65.5 \mathrm{~kg} / \mathrm{s}$ is selected according to typical conditions for the Upper Rhine Rift Valley, one of the most suitable regions for geothermal power generation in Germany.

To evaluate cycle performance the net second law efficiency $\eta_{\text {II }}$ is calculated according to:

$$
\eta_{\mathrm{II}}=\frac{\left|P_{G}+P_{P}\right|}{\dot{E}_{G F}}=\frac{P_{n e t}}{\dot{m}_{G F} \cdot e}
$$

Here $P_{G}$ corresponds to the generated power of the system and $P_{P}$ represents the power applied by the pump. The maximum power output of geothermal source, the exergy flow $\dot{E}_{G F}$, is obtained by multiplying the specific exergy $e$ of the geothermal fluid with its mass flow $\dot{m}_{G F}$. The specific exergy $e$ is calculated according to:

$$
e=h-h_{0}-T_{0}\left(s-s_{0}\right)
$$

where the state variable $T_{0}$ is set to $15{ }^{\circ} \mathrm{C}$ and $p_{0}=1.5 \mathrm{MPa}$. 
As an indicator for the dimensions of heat exchange equipment, the heat exchange capacity $U A$ is calculated for each heat exchanger (see Equation 3). Therefore, the transferred thermal energy $\dot{Q}$ is divided by the logarithmic mean temperature difference $\Delta T_{\log }$ :

$$
\begin{gathered}
U A=\frac{\dot{Q}}{\Delta T_{\text {log }}} \\
\Delta T_{\text {log }}=\frac{\Delta T_{\text {in }}-\Delta T_{\text {out }}}{\ln \left(\frac{\Delta T_{\text {in }}}{\Delta T_{\text {out }}}\right)}
\end{gathered}
$$

$\Delta T_{\text {in }}$ and $\Delta T_{\text {out }}$ correspond to the temperature difference between ORC working fluid and heat source or sink at the inlet and outlet of the heat exchanger. The $U A$ parameter is only suitable for qualitative comparisons and serves as a rough impression of the required heat exchanger dimensions. For a comprehensive thermo-economic evaluation the heat exchange surfaces have to be determined. This includes the application of suitable heat transfer correlations and geometries. In the following, the selected design criteria are described.

Table 1. Boundary conditions assumed for the second law analysis.

\begin{tabular}{lc}
\hline Parameter & Value \\
\hline Mass flow rate of geothermal fluid $\dot{m}_{g f}(\mathrm{~kg} / \mathrm{s})$ & 65.5 \\
Inlet temperature of geothermal fluid $T_{G F, \text { in }}\left({ }^{\circ} \mathrm{C}\right)$ & $80-180$ \\
Pressure of geothermal fluid $p_{g f}(\mathrm{bar})$ & 15 \\
Minimal reinjection temperature $T_{G F, \text { rein }}\left({ }^{\circ} \mathrm{C}\right)$ & 25 \\
Minimal temperature difference internal heat exchanger $\Delta T_{P P, I H E}(\mathrm{~K})$ & 5 \\
Minimal temperature difference preheater $\Delta T_{P P, P H E}(\mathrm{~K})$ & 5 \\
Minimal temperature difference condenser $\Delta T_{P P, C O N D}(\mathrm{~K})$ & 5 \\
Temperature difference of the cooling medium $\Delta T_{C M}(\mathrm{~K})$ & 5 \\
Inlet temperature of cooling medium $T_{C M, i n}\left({ }^{\circ} \mathrm{C}\right)$ & 15 \\
Maximal ORC process pressure $p_{2}($ bar $)$ & $0.8 \cdot p_{c r i t}$ \\
Isentropic efficiency of feed pump $\eta_{i, P}(\%)$ & 75 \\
Isentropic efficiency of turbine $\eta_{i, T}(\%)$ & 80 \\
Efficiency of generator $\eta_{i, G}(\%)$ & 98 \\
\hline
\end{tabular}

\subsection{Heat Exchanger Design}

In this study we consider shell and tube heat exchanger. The geothermal fluid is passed inside the pipes due to higher fouling tendency. In case of the condenser, the ORC working fluid is inside the pipes. In order to calculate the required diameter of the shell and number of tubes, maximal flow velocities are assumed according to chapter O1 of the VDI Heat Atlas [44]. These are $2 \mathrm{~m} / \mathrm{s}$ for liquid and $20 \mathrm{~m} / \mathrm{s}$ for gaseous media. The inner diameter of the tubes is $20 \mathrm{~mm}$ and the wall thickness of tube is $2 \mathrm{~mm}$. A triangular layout and a pitch to diameter ratio of 1.3 are assumed. Depending on phase state and flow configuration corresponding heat transfer correlations are applied. For the calculation of heat transfer of turbulent, single phase flow in a plain tube the model according to Sieder and Tate [47] is used. The corresponding Nusselt number $N u$ depends on the Reynolds number $R e$ and the Prandtl 
number Pr. The model is applied for the geothermal fluid in the preheater and evaporator as well as for the working fluid in the internal heat exchanger:

$$
N u=0.027 \operatorname{Re}^{0.8} \operatorname{Pr}^{0.33}
$$

The single phase heat transfer on the shell side is predicted according to Kern [48]:

$$
N u=0.36 \operatorname{Re}^{0.55} \operatorname{Pr}^{0.33}
$$

In case of the evaporation of pure working fluids on a plain tube the correlation for pool boiling derived from Stephan and Abdelsalam [49] is applied:

$$
N u=207 \cdot\left(\frac{\dot{q} \cdot d}{\lambda_{l} \cdot T_{s}}\right)^{0.745} \cdot\left(\frac{\rho_{g}}{\rho_{l}}\right)^{0.581} \cdot\left(\frac{v_{l}}{a_{l}}\right)^{0.533}
$$

Here the index $l$ represents the liquid phase and $g$ corresponds to the gaseous phase. For the considered correlation the heat transfer depends on heat flux density $\dot{q}$, diameter of the tube $d$, thermal conductivity $\lambda$, saturation temperature $T_{S}$, density $\rho$, viscosity $v$ and thermal diffusivity $a$.

Considering the evaporation of fluid mixtures, a reduction of heat transfer has to be taken into account. Lower heat transfer coefficients compared to pure fluids occur due to additional mass transfer. In this context, diffusion processes of the more volatile component to the heating surface have to be taken into account. Several models describe the deviation of the heat transfer coefficient $\alpha$ of zeotropic two-component mixtures from an ideal value $\alpha_{i d}$, which represents the linear interpolation between the values for pure components. Heberle et al. [50] show that for potential binary mixtures used as ORC working fluids the model of Schlünder [51] is applicable:

$$
\frac{\alpha_{i d}}{\alpha}=1+\frac{\alpha_{i d}}{\dot{q}} \cdot\left(T_{s 2}-T_{s 1}\right) \cdot\left(y_{1}-x_{1}\right) \cdot\left(1-\exp \left(-B_{0} \cdot \frac{\dot{q}}{\rho_{l} \cdot \beta \cdot \Delta h_{v}}\right)\right)
$$

Here $\beta$ as well as $B_{0}$ represent experimental fitted constants. The following assumptions are made: $\beta=2 \times 10^{-4} \mathrm{~m} / \mathrm{s}$ and $B_{0}=1$. The mole fraction of liquid and gaseous phase of the component $i$ correspond to $x_{i}$ and $y_{i}$. The temperatures $T_{s i}$ describe the saturation temperature of the mixture component.

Finally, the condensation of a pure working fluid in plain tubes is calculated according to the correlation of Shah [52].

$$
N u=0.023 \cdot \operatorname{Re}_{l}^{0.8} \cdot \operatorname{Pr}_{l}^{0.4} \cdot\left[(1-x)^{0.8}+\frac{3.8 \cdot x^{0.76} \cdot(1-x)^{0.04}}{p^{* 0.38}}\right]
$$

Here $x$ represents the vapour quality and $p^{*}$ corresponds to the reduced pressure $\left(p^{*}=p_{O R C} / p_{c r i t}\right)$. In analogy to the evaporation process, a reduction of heat transfer due to additional mass transfer has to be considered for zeotropic mixtures. Therefore, we apply the method of Sliver, Bell and Ghaly [53,54]. In Equation (10) $\alpha_{\text {eff }}$ represents the heat transfer coefficient for the zeotropic mixture, while $\alpha(x)$ is calculated according to Equation (9) using fluid properties of the fluid mixture. For heat transfer coefficient in the gaseous phase $\alpha_{g}$ Equation (11) is applied:

$$
\frac{1}{\alpha_{e f f}}=\frac{1}{\alpha(x)}+\frac{Z_{g}}{\alpha_{g}}
$$




$$
\begin{gathered}
N u=0.023 \cdot R e_{g}^{0.8} \cdot \operatorname{Pr}_{g}^{0.4} \\
Z_{g}=x \cdot c_{p, g} \cdot \frac{T_{G, \text { Cond }}}{\Delta h}
\end{gathered}
$$

The parameter $Z_{g}$ is the ratio between the sensible part of the condensation of the zeotropic mixture and the latent part. Here $c_{p, g}$ represents the heat capacity of the gaseous phase, $T_{G, C o n d}$ the temperature glide at condensation and $\Delta h$ the corresponding enthalpy difference.

The overall heat transfer coefficient $U_{\text {tot }}$ of each heat exchanger is calculated by:

$$
\frac{1}{U_{t o t}}=\frac{1}{\alpha_{o}}+\frac{1}{\alpha_{i}} \frac{r_{o}}{r_{i}}+\frac{r_{o} \ln \left(r_{o} / r_{i}\right)}{\lambda_{t}}
$$

where $\alpha_{o}$ represents the heat transfer coefficient at the outside of the tube, respectively, shell side and $\alpha_{i}$ corresponds to the heat transfer coefficient at the inside of the tube. The inner and outer radius of the tube are represented by $r_{i}$ and $r_{o}$. The thermal conductivity of the tube corresponds to $\lambda_{t}$. Finally, the required heat transfer surface is determined according to Equation (3), including a safety factor of 1.2.

\subsection{Cost Estimations}

Based on the determined heat transfer surfaces and capacities of the rotating equipment $Y$, cost estimations for each component are conducted. Turton et al. [55] collect data for purchased equipment costs (PEC) by survey of component manufacturers. The authors introduce a general equation for the purchased equipment costs in US Dollar $C_{0}$ at ambient operating conditions and using carbon steel construction:

$$
\log _{10} C_{0}=K_{1}+K_{2} \cdot \log _{10}(Y)+K_{3}\left(\log _{10}(Y)\right)^{2}
$$

Due to maximal pressures of the ORC below 35 bar, additional cost factors depending on system pressure are not considered. The parameter $K_{1}, K_{2}$ and $K_{3}$ are listed for the considered main components in Table 2. In addition, minimal and maximal values for $Y$ are included. If a component exceeds the maximal value several parallel arranged components are considered. The listed cost data are from the year 2001. By setting the corresponding Chemical Engineering Cost Plant Index (CEPCI) of 397 into relation to the value of May 2014 with 574, inflation and the development of raw material prices are taken into account. To convert the PEC in Euro a conversion ratio of 0.8 (as at 10 December 2014) is considered. The total investment costs of the ORC power plant $C_{t o t, O R C}$ are calculated by multiplying the sum of the PEC by the factor 6.32. According to Bejan et al. [56] this parameter represents additional costs like installation, piping, controls, basic engineering and others in relation to the purchased equipment costs of the major components.

Table 2. Equipment cost data used for Equation (14) according to Turton et al. [55].

\begin{tabular}{ccccccc}
\hline Component & $\boldsymbol{Y}$; unit & $\boldsymbol{K}_{\mathbf{1}}$ & $\boldsymbol{K}_{\mathbf{2}}$ & $\boldsymbol{K}_{\mathbf{3}}$ & $\boldsymbol{Y}_{\min }$ & $\boldsymbol{Y}_{\max }$ \\
\hline Pump (centrifugal) & $\mathrm{kW}$ & 3.3892 & 0.0536 & 0.1538 & 1 & 300 \\
Heat exchanger (floating head) & $\mathrm{m}^{2}$ & 4.8306 & -0.8509 & 0.3187 & 10 & 1000 \\
Turbine (axial) & $\mathrm{kW}$ & 2.7051 & 1.4398 & -0.1776 & 100 & 4000 \\
\hline
\end{tabular}




\subsection{Economic Parameters}

As economic performance parameters the specific investment costs SIC of ORC power plant and the electricity generation costs $E G C$ are calculated. In order to determine $E G C$ for the geothermal power plant a lifetime $n$ of 30 years is assumed [57]. In addition, financial linked costs $C_{F}$ have to be calculated. Therefore, exploration costs with 16.5 million $€$ and costs for land and an insurance with 2 million $€$ are assumed [38]. Other costs are set as 3\% of the total investment costs. Costs for operation and maintenance $\operatorname{Co\& M}$, including personnel costs, are set to $2 \%$ of the total investment costs. The credit period is 20 years and the interest rate is $6.5 \%$. Annual operation hours of $8,000 \mathrm{~h} / \mathrm{a}$ are assumed to calculate the annual amount of generated electricity Eannual:

$$
\begin{gathered}
S I C=\frac{C_{\text {tot }, \text { ORC }}}{P_{\text {net }}} \\
E G C=\frac{\sum_{i=1}^{n} \frac{C_{F, i}+C_{O \& M, i}}{E_{\text {annual }}}}{n}
\end{gathered}
$$

\section{Results and Discussion}

\subsection{Selection of Zeotropic Fluid Mixtures}

Since a good glide matching in the condenser is favorable for an efficiency increase, the temperature glide at condensation conditions $\left(T_{1}=25^{\circ} \mathrm{C}\right)$ is a major selection criteria for potential mixtures. In this context a ratio between temperature difference of the cooling medium and temperature glide of the zeotropic mixture at condensation equal 1 is favourable. Therefore, zeotropic mixtures showing a maximum temperature glide $T_{G \text {, max }}$ below $3 \mathrm{~K}$ at condensation are excluded in this study. Mixture components of different class of substances are not taken into account for this study with respect to reliability of fluid properties. Components with high differences of saturation temperature, like water and ammonia, are disregarded. These mixtures are more suitable for separation processes like the Kalina Cycle. In addition, uncertainties for heat transfer correlations and significant concentration shifts have to be expected. Predefined ternary or multi-component mixtures, like R404a or R417a, well-known from air-conditioning or refrigeration, are not considered because of chlorinated components, azeotropic characteristics or low temperature glides. The investigated fluid mixtures are listed in Table 3. Furthermore, the maximum temperature glide at condensation and evaporation conditions, wet (-) or dry $(+)$ characteristics and considered references to predict the fluid properties are presented. For some mixtures, a change of the characteristics occur depending on mixture composition $(-/+)$. 
Table 3. Maximum temperature glides at condensation and evaporation conditions, slope of the dew line and references for fluid property prediction of the investigated fluid mixtures

\begin{tabular}{ccccc}
\hline Fluid Mixture & $\boldsymbol{T}_{\boldsymbol{G}, \boldsymbol{m a x}}\left({ }^{\circ} \mathbf{C}\right) \boldsymbol{a} \boldsymbol{T}_{\mathbf{1}}=\mathbf{2 5}{ }^{\circ} \mathbf{C}$ & $\boldsymbol{T}_{\boldsymbol{G}, \boldsymbol{m a x}}\left({ }^{\circ} \mathbf{C}\right) \boldsymbol{a} \boldsymbol{T}_{\mathbf{4}}=\mathbf{8 0}{ }^{\circ} \mathbf{C}$ & $\mathbf{d} \boldsymbol{T} / \mathbf{d} \boldsymbol{s}$ & Reference \\
\hline $\mathrm{R} 134 \mathrm{a} / \mathrm{R} 236 \mathrm{fa}$ & 6.05 & 4.00 & $-/+$ & {$[58]$} \\
$\mathrm{R} 134 \mathrm{a} / \mathrm{R} 245 \mathrm{fa}$ & 15.14 & 11.13 & $-/+$ & {$[58]$} \\
$\mathrm{R} 134 \mathrm{a} / \mathrm{RC} 318$ & 5.17 & 3.52 & + & {$[58]$} \\
$\mathrm{R} 152 \mathrm{a} / \mathrm{R} 245 \mathrm{fa}$ & 12.70 & 8.99 & $-/+$ & {$[58]$} \\
$\mathrm{R} 227 \mathrm{ea} / \mathrm{R} 245 \mathrm{fa}$ & 9.51 & 6.33 & + & {$[58]$} \\
$\mathrm{R} 236 \mathrm{fa} / \mathrm{R} 365 \mathrm{mfc}$ & 15.63 & 12.22 & + & {$[58]$} \\
$\mathrm{R} 245 \mathrm{fa} / \mathrm{R} 365 \mathrm{mfc}$ & 6.50 & 5.92 & + & {$[58]$} \\
propane/isobutane & 7.21 & 5.14 & $-/+$ & {$[59]$} \\
$n$-butane/n-pentane & 10.45 & 8.60 & + & {$[59]$} \\
isobutane/isopentane & 12.21 & 9.90 & + & {$[59]$} \\
$n$-pentane/ $n$-hexane & 8.55 & 7.27 & + & {$[59]$} \\
isohexane/ $n$-pentane & 4.32 & 3.67 & + & {$[58]$} \\
\hline
\end{tabular}

\subsection{Reliability of Fluid Properties}

Regarding the reliability of fluid properties for pure working fluids and mixtures, predicted vapour pressure, VLE and density data are compared to experimental data. Exemplarily, Figure 2 shows the vapour pressure for R134a, n-butane, R245fa and n-pentane calculated by REFPROP [60-63]. For R134a, the experimental data of Valtz et al. [64] and the prediction model are in good agreement. The mean relative deviation is $0.2 \%$ and the maximum relative deviation of $0.5 \%$ occurs for high temperatures. In case of $n$-butane, the experimental data of Warowny [65] show a maximum deviation of $3.0 \%$ and a mean relative deviation of $2.3 \%$. For $n$-pentane, the vapour pressure measured by Abdulagatov und Rasulov [66] lead to a mean relative deviation of $1.4 \%$ compared to REFPROP.

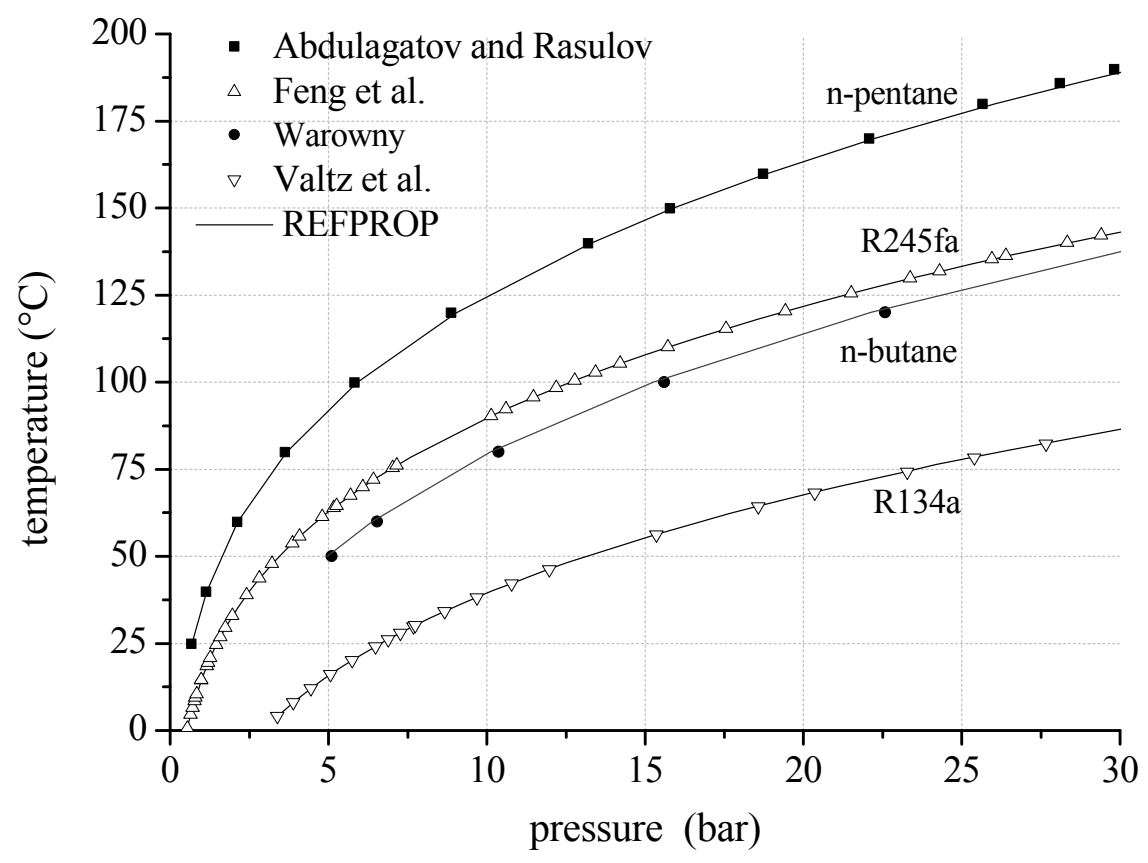

Figure 2. Vapour pressure calculated by REFPROP compared to experimental data for selected ORC working fluids. 
The maximum relative deviation of $-2.4 \%$ arise near critical conditions $\left(T_{\text {crit }}=196.6{ }^{\circ} \mathrm{C}\right)$. Vapour pressure measurements of R245fa by Feng et al. [67] show a mean relative deviation of $0.4 \%$ compared to REFPROP. The maximum relative deviation of $-2.1 \%$ is related to low temperatures.

In the case of the evaluation of fluid properties for the considered mixtures, a distinction between natural hydrocarbons and fluorinated hydrocarbons has to be made. In case of natural hydrocarbons as mixture components, the required binary coefficients for the mixing rule of Kunz et al. [59] are available in literature and implemented in REFPROP. $N$-pentane/isohexane represents the only exception for mixtures of this class of substance. In this case, as well as for mixtures of fluorinated components, the generalized factors and mixture parameters for the equation of state are estimated by REFPROP. Regarding natural hydrocarbons, Figure 3 shows experimental and theoretical VLE data of the binary mixtures $n$-butane/ $n$-pentane and propane/isobutane. The measurements of Calingaert and Hitchcock [68] lead to a mean relative deviation of $3.4 \%$ compared to REFPROP. The maximum relative deviation is $10.8 \%$. In case of propane/isobutane the mean relative deviation is $0.8 \%$ compared to the experimental data of Lim et al. [69].

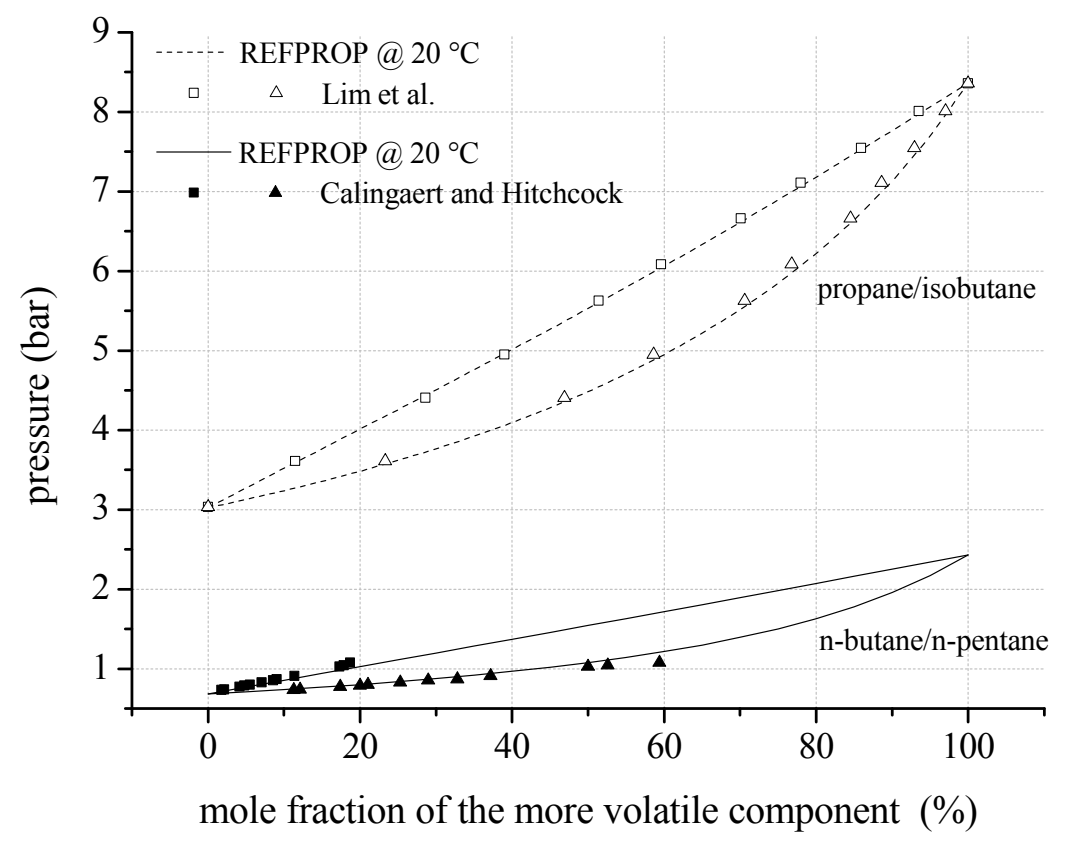

Figure 3. VLE data calculated by REFPROP compared to experimental data for fluid mixtures considering natural hydrocarbons as mixture components.

To evaluate the uncertainties resulting from predicted mixing factors and parameters, Figure 4 shows VLE data of mixtures consisting of fluorinated components compared to REFPROP. In case of R134a/R245fa, experimental data of Bobbo et al. [70] show a mean relative deviation of $4.7 \%$ compared to REFPROP. Regarding the liquid phase, the mean relative deviation is $5.1 \%$ and for the gaseous phase $4.4 \%$. The maximum relative deviation of $-11.0 \%$ arises in the liquid phase. For R134a/R236fa a mean relative deviation of $4.9 \%$ is determined comparing data of Bobbo et al. [71] and REFPROP. The maximum relative deviation of $-10.1 \%$ occurs in the gaseous phase. Additionally, fluid properties of R142b/R134a are compared to experimental VLE data of Kleiber [72]. Here, a mean relative deviation of $3.3 \%$ is obtained. For the examined zeotropic mixtures consisting of fluorocarbons, the comparisons show similar deviations as determined for mixtures with natural hydrocarbon components. 


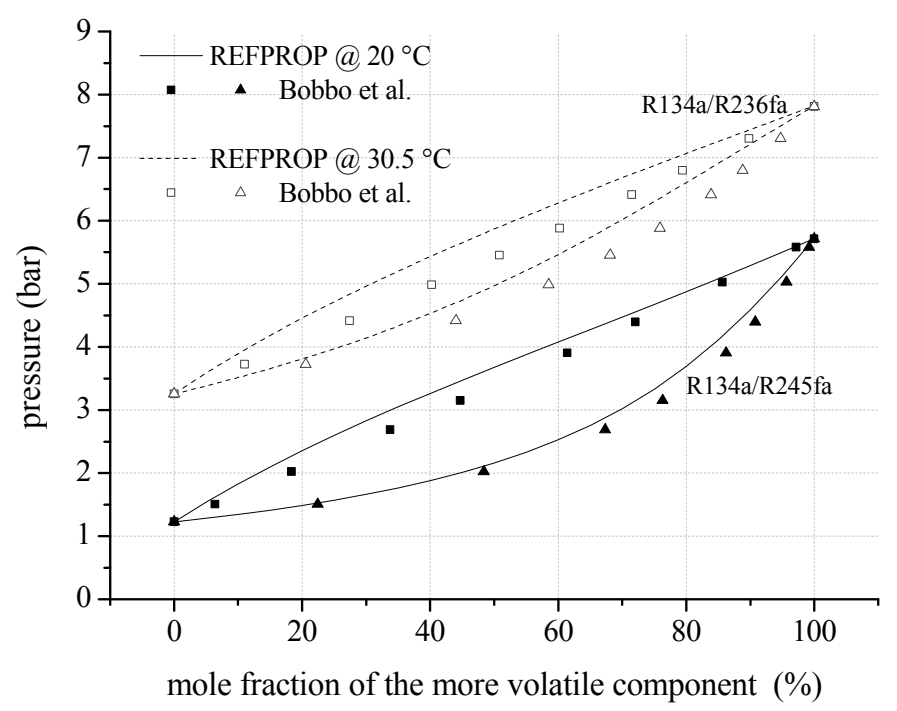

Figure 4. VLE data calculated by REFPROP compared to experimental data for fluid mixtures regarding fluorinated hydrocarbons as mixture components.

As an alternative to vapour pressure and VLE-data, experimental data for density are analyzed. According to Figure 5a, gaseous density for $n$-pentane measured by Abdulagatov and Rasulov [66] show a mean relative deviation of $2.6 \%$ to REFPROP. In case of liquid density, mean relative deviation is $1.0 \%$. The uncertainties increase with increasing temperature. Near critical conditions the maximum relative deviation is $10.8 \%$. A limitation of the maximum ORC process pressure according to Table 1 leads to a maximum relative deviation of $1.8 \%$ in the gaseous phase and $0.4 \%$ in the liquid phase. Experimental data for density of the selected zeotropic mixtures are available for propane/isobutane. Kayukawa and Watanabe [73] examined the liquid density at constant temperature depending on pressure for three mixture compositions. Figure $5 \mathrm{~b}$ shows the liquid density for $26.85{ }^{\circ} \mathrm{C}$ as a function of mixture composition and pressure. Considering the complete available data set, a mean relative deviation of $0.15 \%$ is determined.

(a)

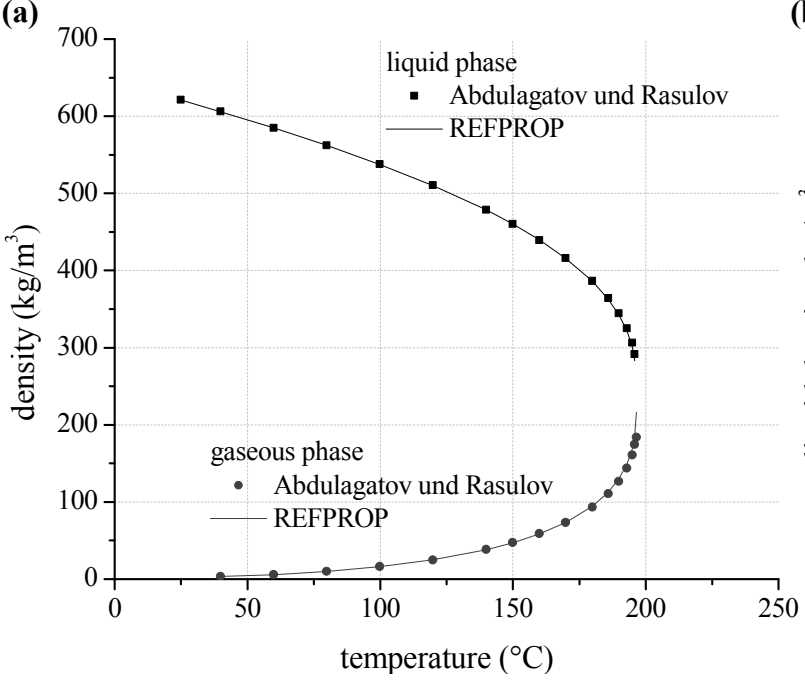

(b)

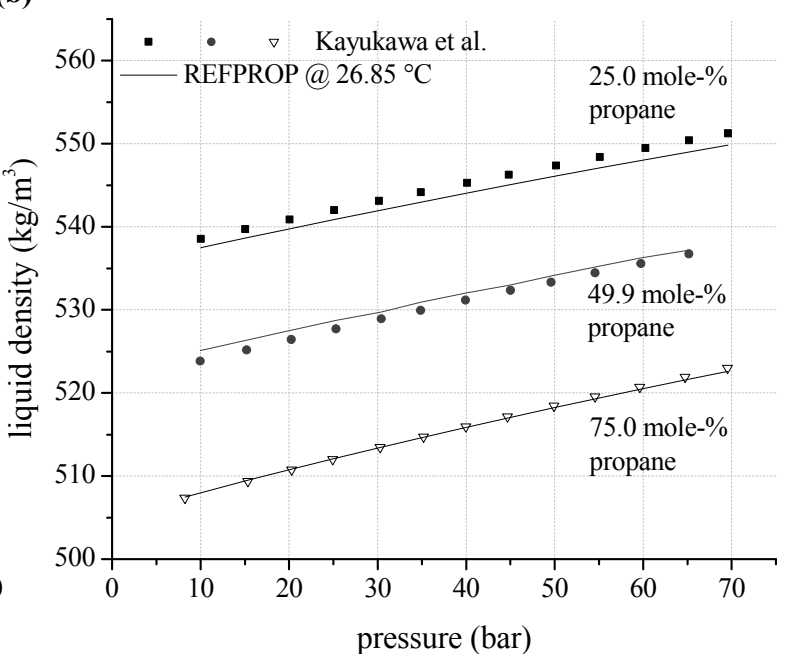

Figure 5. (a) Predicted liquid and gaseous density depending on temperature compared to experimental data for $n$-pentane; (b) liquid density as a function of mixture composition and pressure calculated by REFPROP compared to experimental data for propane/isobutane. 
In general the experimental data show a good agreement to the predictions models. In this context, REFPROP is suitable for process simulations of ORC systems using pure working fluids and zeotropic mixtures. For pure fluids, the determined deviations correspond quiet well with the uncertainties of prediction models, which range between $0.2 \%$ and $1.0 \%$ for density as well as for vapour pressure. Higher deviations are only obtained near critical conditions and for those mixtures, where mixture parameters for the equation of state are estimated.

\subsection{Second Law Analysis}

We examined the second law efficiency of the ORC depending on inlet temperature of the geothermal fluid in the range of 80 and $180^{\circ} \mathrm{C}$. Figure 6a shows the exergetic efficiency as a function of heat source temperature for ORC systems using pure natural hydrocarbons as working fluids. For temperatures below $130{ }^{\circ} \mathrm{C}$, relative differences of second law efficiency are maximal $5 \%$. Considering the homologous series of alkanes, starting from isobutane, the margin of fluctuation related to fluid selection is low. More volatile components lead to more efficient cycles; this is also applicable for higher heat source temperatures. The ranking correlates with the critical temperature, too. Second law efficiency increases with rising temperature except choosing propane as a working fluid. For propane, an efficiency optimum at $140{ }^{\circ} \mathrm{C}$ is obtained due to a shift of the pinch-point from the preheater outlet to the inlet. Additionally, an expansion into the two-phase region has to be taken into account, evaluating propane as working fluid. A minimal vapour quality of $94.9 \%$ at the turbine outlet is determined for $130{ }^{\circ} \mathrm{C}$ inlet temperature of the geothermal fluid. However, compared to isopentane the second law efficiency is increased by up to $21.9 \%$ for the use of propane as a working fluid. For temperatures higher than $150{ }^{\circ} \mathrm{C}$, the efficiency decreases below alternatively considered hydrocarbons.

(a)

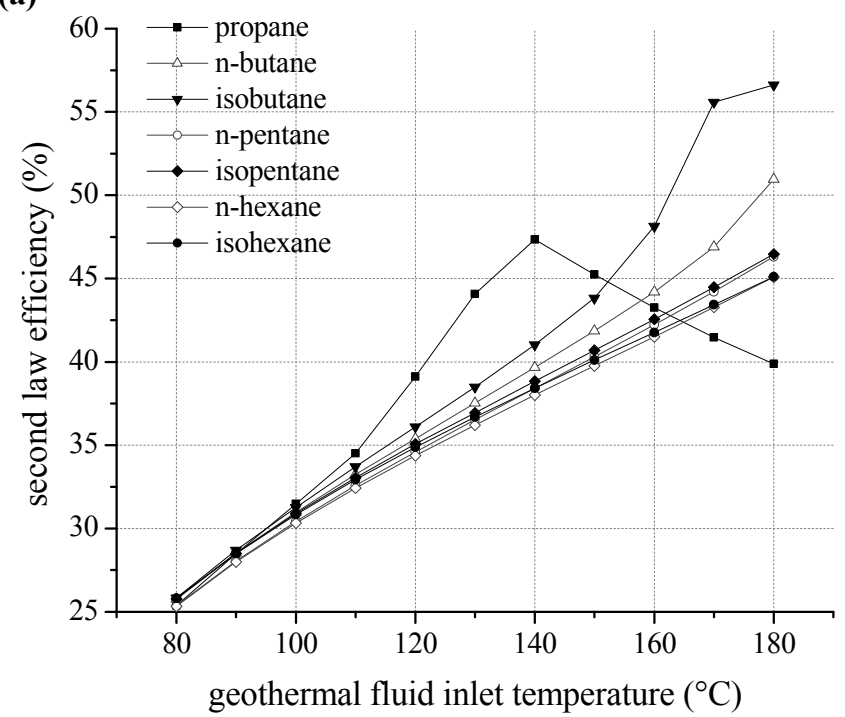

(b)

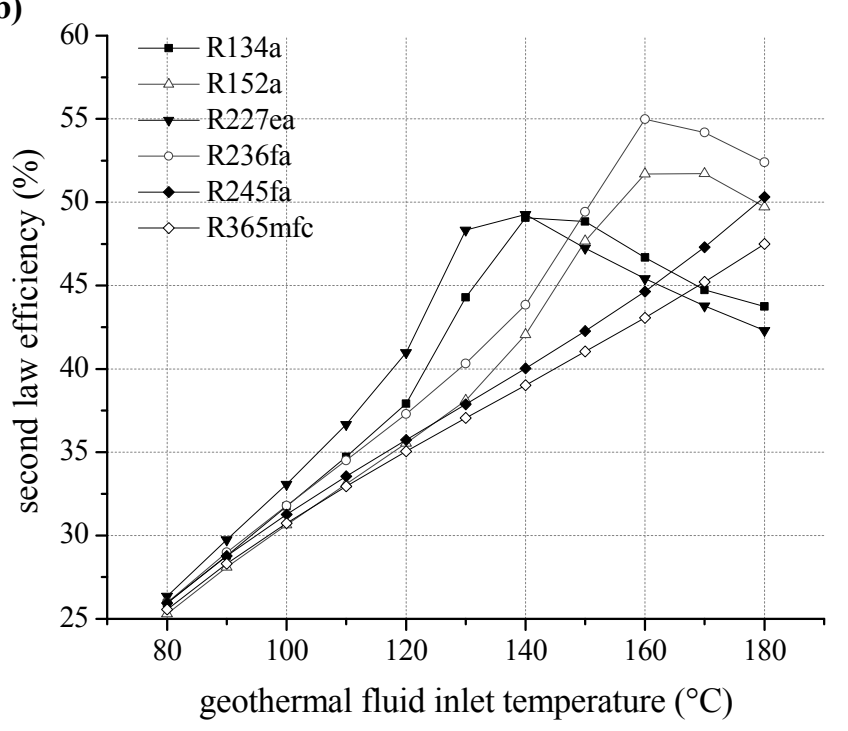

Figure 6. Second law efficiency as a function of heat source temperature for ORC systems using pure working fluids (a) natural hydrocarbons (b) fluorinated hydrocarbons.

For fluorinated hydrocarbons a correlation between critical temperature and second law efficiency is obtained, too (see Figure 6b). For temperatures up to $140{ }^{\circ} \mathrm{C}$ the working fluids R134a and R227ea, with the lowest critical temperatures, lead to the highest efficiency. In analogy to propane, the fluids 
R227ea, R134a, R152a and R236fa show an efficiency optimum of the ORC. In case of R227ea, second law efficiency at $130{ }^{\circ} \mathrm{C}$ is $27.6 \%$ higher compared to the common working fluid R245fa. In general, the optimum is shifted to higher heat source temperatures for fluids with higher critical temperatures. Again, the significant efficiency increase is accompanied by a shift of the pinch-point from the preheater outlet to the inlet. As a consequence, a better match of temperature profiles regarding the ORC and the heat source is obtained. Therefore, the reinjection temperature sinks and a higher amount of thermal power is coupled to the ORC. Figure 7 illustrates this effect by means of a temperature-enthalpy flow-diagram for the cycle with R227ea as ORC working fluid. In case of a heat source temperature of $110{ }^{\circ} \mathrm{C}$ (Figure $7 \mathrm{a}$ ), the ORC is limited by the minimal temperature difference between heat source and cycle at the pinch point, here state point 4 . The process pressure $p_{4}$ of 15.8 bar is below the maximum value of $0.8 \cdot p_{\text {crit. }}$. In case of an inlet temperature of the geothermal fluid of $130{ }^{\circ} \mathrm{C}$ (Figure $7 \mathrm{~b}$ ), the maximum pressure of 23.4 bar is reached. The pinch-point is still at state point 4. For a temperature of $140{ }^{\circ} \mathrm{C}$, the pinch point shifts to the inlet of the preheater, while $p_{4}$ and $T_{4}$ stay constant. This allows a reduction of the reinjection temperature to $37.9^{\circ} \mathrm{C}$ and an efficiency maximum can be observed (see Figure 6b). For R245fa, at same conditions, a reinjection temperature of $65.2{ }^{\circ} \mathrm{C}$ is determined. Thus, 7.4 MW more thermal power is transferred to the ORC using R227ea as a working fluid. The gross power output is $0.9 \mathrm{MW}$ higher compared to R245fa.
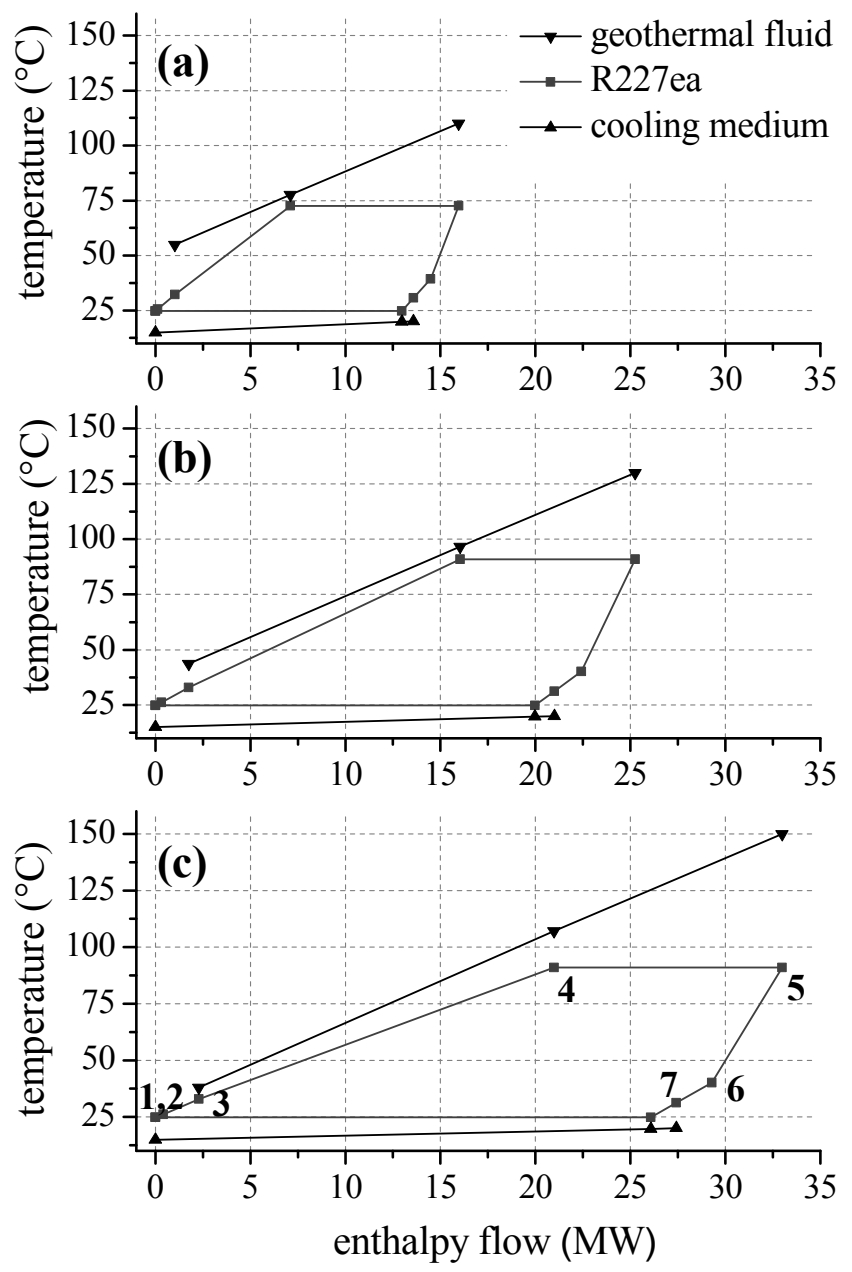

Figure 7. Temperature-enthalpy flow-diagram for the ORC with R227 at different inlet temperature of the geothermal fluid of (a) $110^{\circ} \mathrm{C}$; (b) $130{ }^{\circ} \mathrm{C}$; and (c) $150{ }^{\circ} \mathrm{C}$. 
Regarding geothermal fluid temperatures higher than $140{ }^{\circ} \mathrm{C}$, an adaption of the ORC using R227ea to the heat source characteristics exclusively takes place by increasing the ORC mass flow. Upper process pressure and temperature of the ORC as well as reinjection temperature stay constant (see Figure 7c). As a result, the net second law efficiency decreases.

For ORC systems using zeotropic mixtures as a working fluid, second law efficiency as a function of the inlet temperature of the geothermal fluid is illustrated in Figure 8. Only the most efficient mixture compositions are included in the diagram. In Tables 4 and 5 the corresponding mole fractions are listed. Regarding natural hydrocarbons as mixture components (see Figure 8a), a significant efficiency increase compared to the most efficient pure component is obtained. For heat source temperatures lower than $100{ }^{\circ} \mathrm{C}$ isobutane/isopentane leads to an efficiency increase between $12.2 \%$ and $18.6 \%$ in relation to isobutane. For higher temperatures propane/isobutane is suitable as working fluid. Compared to propane, a higher efficiency in the range of $2.1 \%$ and $20.6 \%$ is obtained. Considering fluorinated hydrocarbons as ORC working fluids a comparable efficiency increase is observed. Figure $8 \mathrm{~b}$ shows the second law efficiency for the considered zeotropic mixtures based on fluorocarbons depending on inlet temperature of the geothermal fluid. For the examined temperature range, R227ea/R245fa leads to high exergetic efficiencies. Compared to the most efficient pure fluid, the increase is up to $17.3 \%$. Only for a heat source temperature of $130{ }^{\circ} \mathrm{C}$, pure R227ea is the most efficient working fluid due to the described shift of the pinch-point. Otherwise zeotropic mixtures lead to an efficiency increase of minimal 5.4\% and maximal 20.6\%. Considering geothermal fluid temperatures below $130{ }^{\circ} \mathrm{C}$ additionally R134a/R236fa and R134a/R245fa are favourable. In the case of higher temperatures, next to R227ea/R245fa, R236fa/R365mfc and R236fa/R245fa are suitable.

(a)

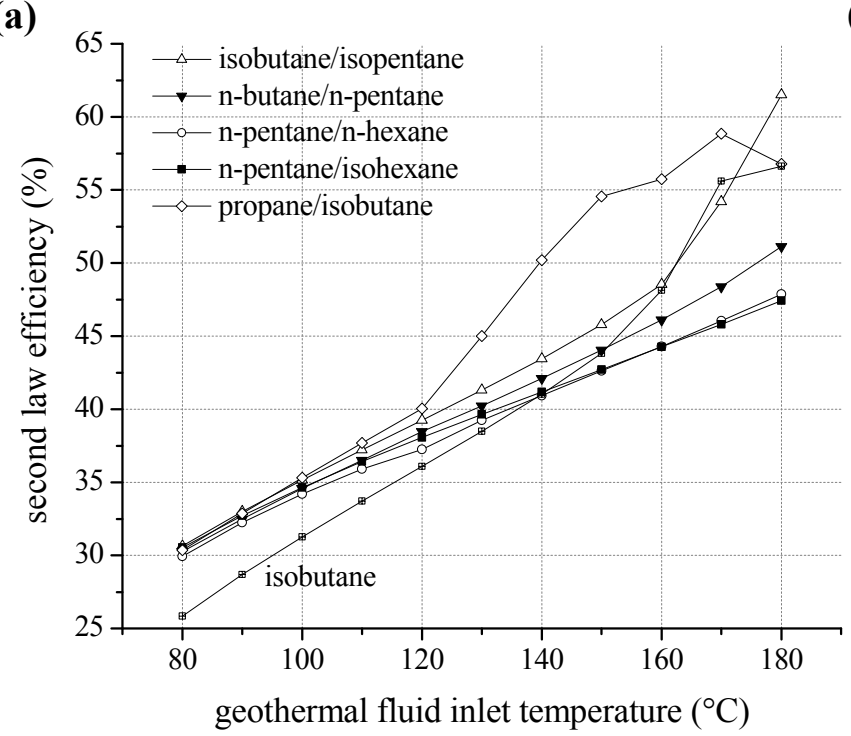

(b)

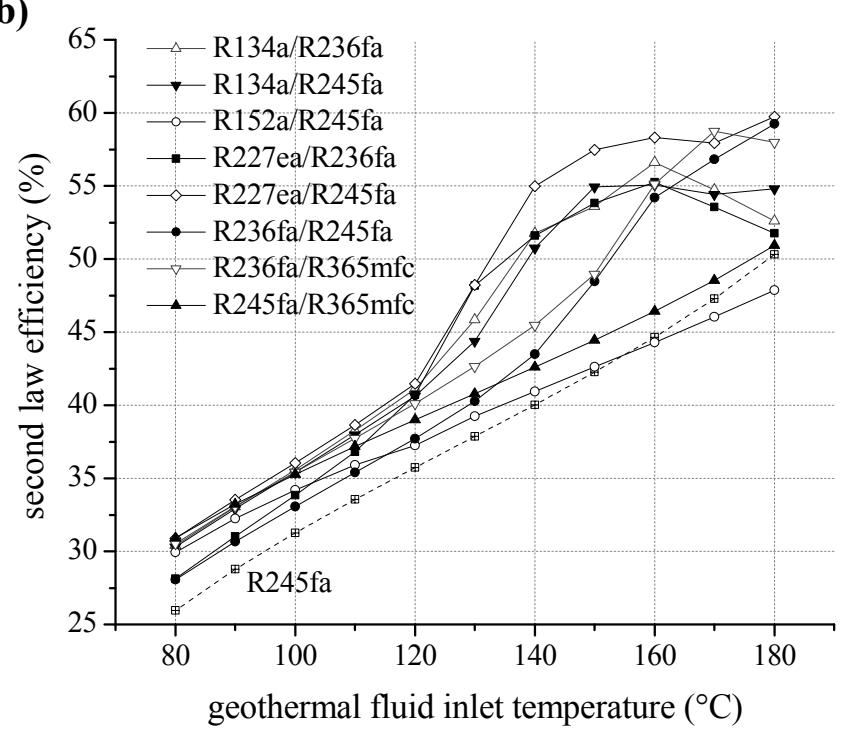

Figure 8. Second law efficiency as a function of heat source temperature for ORC systems using zeotropic mixtures as working fluids (a) natural hydrocarbons (b) fluorinated hydrocarbons. 
Table 4. Most efficient mixture compositions (mole fractions) corresponding to Figure 8a.

\begin{tabular}{cccccc}
\hline $\begin{array}{c}\boldsymbol{T}_{\boldsymbol{G F}, \boldsymbol{i n}} \\
\left({ }^{\circ} \mathbf{C}\right)\end{array}$ & $\begin{array}{c}\text { Isobutane/ } \\
\text { Isopentane }\end{array}$ & $\begin{array}{c}\boldsymbol{n} \text {-Butane/ } \\
\boldsymbol{n} \text {-Pentane }\end{array}$ & $\begin{array}{c}\boldsymbol{n} \text {-Pentane/ } \\
\boldsymbol{n} \text {-Hexane }\end{array}$ & $\begin{array}{c}\boldsymbol{n} \text {-Pentane/ } \\
\text { Isohexane }\end{array}$ & $\begin{array}{c}\text { Propane/ } \\
\text { Isobutane }\end{array}$ \\
\hline 80 & $90 / 10$ & $80 / 20$ & $80 / 20$ & $50 / 50$ & $80 / 20$ \\
90 & $90 / 10$ & $90 / 10$ & $80 / 20$ & $50 / 50$ & $80 / 20$ \\
100 & $90 / 10$ & $90 / 10$ & $80 / 20$ & $50 / 50$ & $80 / 20$ \\
110 & $90 / 10$ & $90 / 10$ & $80 / 20$ & $50 / 50$ & $80 / 20$ \\
120 & $90 / 10$ & $90 / 10$ & $80 / 20$ & $50 / 50$ & $80 / 20$ \\
130 & $90 / 10$ & $90 / 10$ & $80 / 20$ & $50 / 50$ & $90 / 10$ \\
140 & $90 / 10$ & $90 / 10$ & $80 / 20$ & $50 / 50$ & $80 / 20$ \\
150 & $90 / 10$ & $90 / 10$ & $80 / 20$ & $50 / 50$ & $80 / 20$ \\
160 & $90 / 10$ & $90 / 10$ & $80 / 20$ & $50 / 50$ & $50 / 50$ \\
170 & $90 / 10$ & $90 / 10$ & $80 / 20$ & $50 / 50$ & $20 / 80$ \\
180 & $90 / 10$ & $90 / 10$ & $80 / 20$ & $50 / 50$ & $10 / 90$ \\
\hline
\end{tabular}

Table 5. Most efficient mixture compositions (mole fractions) corresponding to Figure $8 \mathrm{~b}$.

\begin{tabular}{|c|c|c|c|c|c|c|c|c|}
\hline $\begin{array}{l}T_{G F, i n} \\
\left({ }^{\circ} \mathbf{C}\right)\end{array}$ & $\begin{array}{l}\text { R134a/ } \\
\text { R236fa }\end{array}$ & $\begin{array}{l}\text { R134a/ } \\
\text { R245fa }\end{array}$ & $\begin{array}{l}\text { R152a/ } \\
\text { R245fa }\end{array}$ & $\begin{array}{c}\text { R227ea/ } \\
\text { R236fa }\end{array}$ & $\begin{array}{c}\text { R227ea/ } \\
\text { R245fa }\end{array}$ & $\begin{array}{l}\text { R236fa/ } \\
\text { R245fa }\end{array}$ & $\begin{array}{l}\text { R236fa/ } \\
\text { R365mfc }\end{array}$ & $\begin{array}{l}\text { R245fa/ } \\
\text { R365mfc }\end{array}$ \\
\hline 80 & $60 / 40$ & $80 / 20$ & $80 / 20$ & $30 / 70$ & $70 / 30$ & $40 / 60$ & $90 / 10$ & $60 / 40$ \\
\hline 90 & $60 / 40$ & $90 / 10$ & $80 / 20$ & $30 / 70$ & $70 / 30$ & $40 / 60$ & $90 / 10$ & $60 / 40$ \\
\hline 100 & $60 / 40$ & $90 / 10$ & $80 / 20$ & $40 / 60$ & $70 / 30$ & $40 / 60$ & $90 / 10$ & $60 / 40$ \\
\hline 110 & $60 / 40$ & $90 / 10$ & $80 / 20$ & $50 / 50$ & $70 / 30$ & $40 / 60$ & $90 / 10$ & $60 / 40$ \\
\hline 120 & $60 / 40$ & $90 / 10$ & $80 / 20$ & $90 / 10$ & $80 / 20$ & $40 / 60$ & $90 / 10$ & $60 / 40$ \\
\hline 130 & $60 / 40$ & $90 / 10$ & $80 / 20$ & $90 / 10$ & $90 / 10$ & $90 / 10$ & $90 / 10$ & $60 / 40$ \\
\hline 140 & $60 / 40$ & $90 / 10$ & $80 / 20$ & $60 / 40$ & $80 / 20$ & $90 / 10$ & $90 / 10$ & $60 / 40$ \\
\hline 150 & $20 / 80$ & $90 / 10$ & $90 / 10$ & $20 / 80$ & $70 / 30$ & $90 / 10$ & $90 / 10$ & $60 / 40$ \\
\hline 160 & $20 / 80$ & $70 / 30$ & $90 / 10$ & $10 / 90$ & $50 / 50$ & $90 / 10$ & $90 / 10$ & $60 / 40$ \\
\hline 170 & $10 / 90$ & $60 / 40$ & $80 / 20$ & $10 / 90$ & $40 / 60$ & $70 / 30$ & $90 / 10$ & $60 / 40$ \\
\hline 180 & $10 / 90$ & $30 / 70$ & $50 / 50$ & $10 / 90$ & $20 / 80$ & $40 / 60$ & $80 / 20$ & $60 / 40$ \\
\hline
\end{tabular}

The selected boundary conditions of our study are in good agreement to Andreasen et al. [28]. Except of the hot fluid mass flow and the minimal temperature difference in the preheater the assumptions are nearly identical. Andreasen et al. [28] identify the most efficient fluids for a heat source temperature at $120{ }^{\circ} \mathrm{C}$. Regarding the considered subcritical cycles, propane/isobutane and isobutane/isopentane were also determined as efficient mixtures. Slight deviations for the most efficient mixture composition occur due to the mentioned differences of boundary conditions and due to the fact we use discrete mole fractions in the sensitivity analysis.

In the following, heat source temperatures of $120{ }^{\circ} \mathrm{C}$ and $160{ }^{\circ} \mathrm{C}$ are selected representatively to analyse the influence of mixture composition on second law efficiency, total $U A$ parameter and economic parameters. In Figure 9 the second law efficiency and the total $U A$ parameter depending on mixture composition are shown for the most efficient zeotropic mixtures in case of a geothermal fluid temperature of $120^{\circ} \mathrm{C}$. 


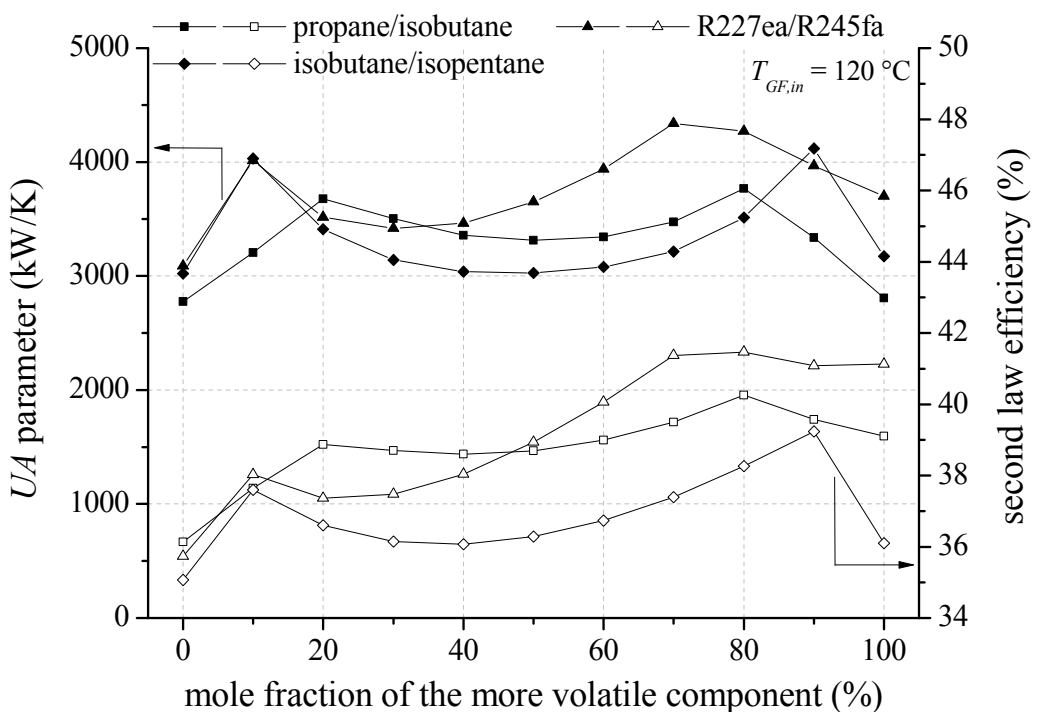

Figure 9. Second law efficiency and $U A$ parameter depending on mixture composition for the most efficient zeotropic mixtures and a geothermal fluid temperature of $120^{\circ} \mathrm{C}$.

Considering the mixture isobutane/isopentane, a mole fraction of $90 \%$ isobutane leads to the highest second law efficiency. For propane/isobutane, a mole fraction of $80 \%$ propane is the most efficient mixture composition. For the mentioned mixture compositions, a glide match of ORC working fluid at condensation occurs. Previous investigations have confirmed that a reduction of irreversibilities in the condenser is mainly responsible for the efficiency increase [18,29]. In contrast, R227ea/R245fa does not show the efficiency maximum at a mixture composition, at which a good glide match takes place. The highest exergetic efficiency is determined for a mole fraction of $80 \%$ R227ea, while the best glide match of the temperature profile arises for a mole fraction of $30 \%$ R227ea. For fluid mixtures, which show a shift of the pinch-point, the possibility to influence this effect to higher heat source temperatures by adding a less volatile component is of primary importance. Accordingly, for R227ea/R245fa the mole fraction of R245fa increases with increasing heat source temperature starting from $130{ }^{\circ} \mathrm{C}$ (see Table 5). This principle can also be observed in Table 4 for propane/isobutane in case of heat source temperatures higher than $150{ }^{\circ} \mathrm{C}$. If a shift of the pinch point does not occur, like for isobutane/isopentane or R245fa/R365mfc, the most efficient mixture composition is independent from the heat source temperature (see Tables 4 and 5). For these mixtures a mole fraction is suitable, which leads to a ratio of $T_{G, \text { Cond }} / \Delta T_{C M}$ equal 1 .

In general, the most efficient mixture composition leads to the highest total $U A$ parameters, Figure 10 shows that the total $U A$ parameter is mainly influenced by the condenser. In case of isobutane/isopentane up to $76.7 \%$ of the total $U A$ parameter is related to the condenser. This is due to a high amount of transferred thermal energy and a low logarithmic temperature difference. In case of zeotropic mixtures the logarithmic temperature difference is even reduced in context of the good glide match. Consequently, pure components in conjunction with the pinch point at the outlet of the preheater lead to low $U A$ parameter due to an isothermal phase-change. The correlation of high efficiency for specific mixture compositions and high $U A$ parameter emphasize the importance of a thermo-economic analysis to clarify if the increase in power output overcompensates the additional heat transfer surface. 


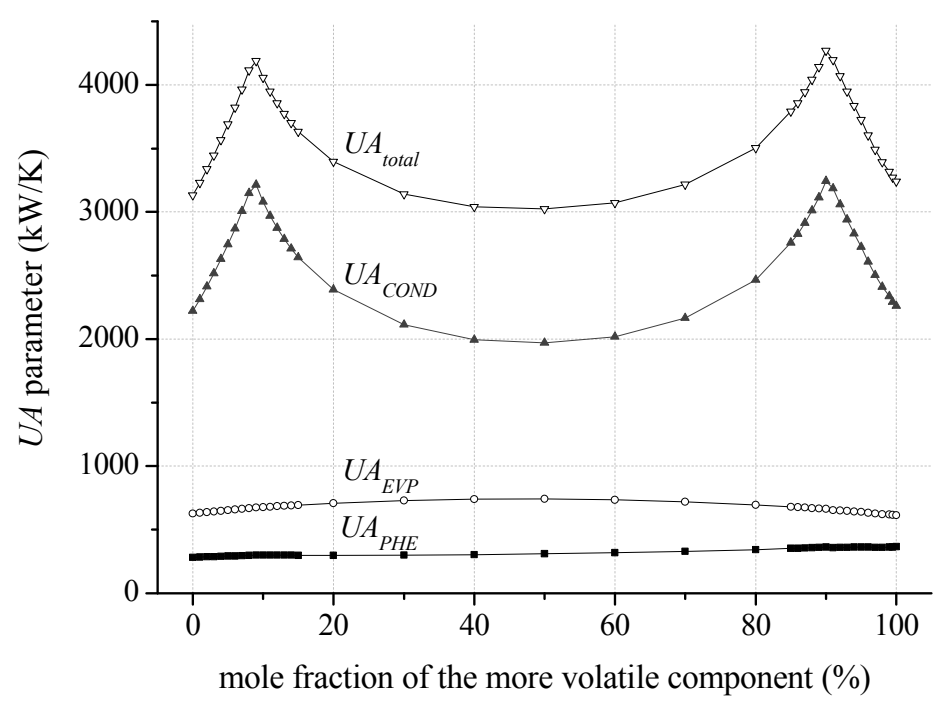

Figure 10. $U A$ parameter for the considered heat exchanger depending on mixture composition of isobutane/isopentane at a geothermal fluid temperature of $120^{\circ} \mathrm{C}$.

For an inlet temperature of the geothermal fluid of $160{ }^{\circ} \mathrm{C}$ the described principles are transferable. Figure 11 shows that high second law efficiency correlates with high UA parameters. For R227ea/R245a, the efficiency optimum occurs at equimolar composition. As mentioned before, the shift of the pinch point is delayed by adding a higher amount of R245fa. Compared to pure R227ea, the second law efficiency can be increased by up to $28.4 \%$. However, the $U A$ parameter is $45.7 \%$ higher in case of the equimolar mixture.

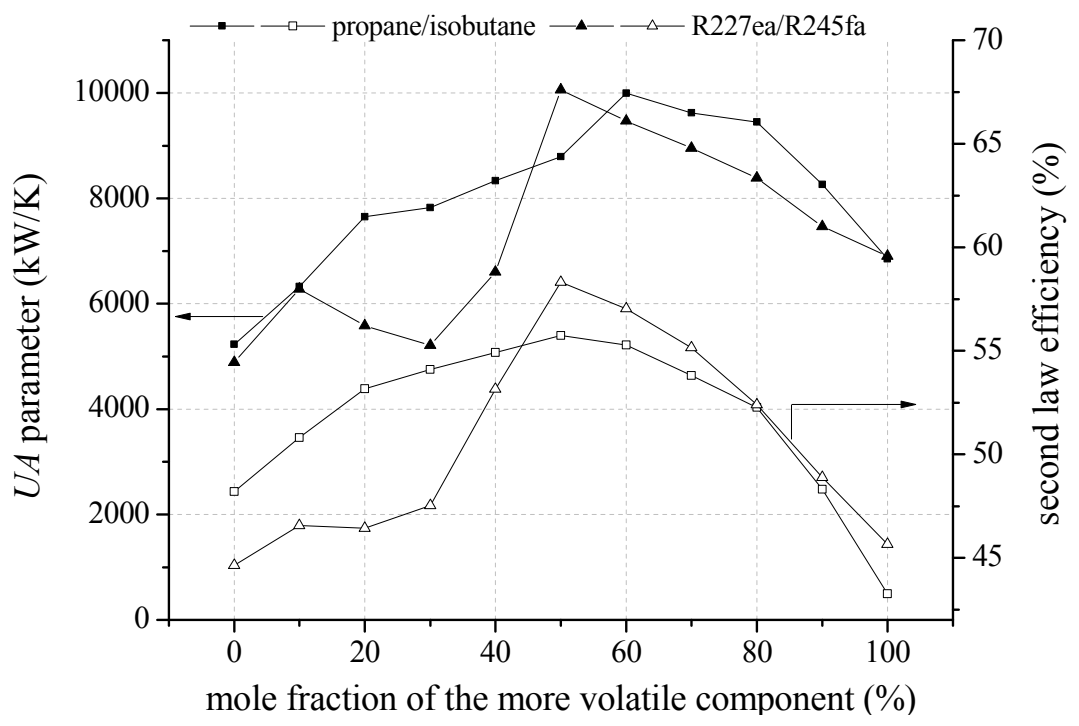

Figure 11. Second law efficiency and $U A$ parameter depending on mixture composition for selected zeotropic mixtures and a geothermal fluid temperature of $160{ }^{\circ} \mathrm{C}$.

Finally, the size parameter of the turbine and the volume flow ratio at the expansion are calculated depending on mixture composition. Regarding isobutane/isopentane and a heat source temperature of $120{ }^{\circ} \mathrm{C}$, the size parameter introduced by Angelino et al. [74] varies in the range of 0.15 and 0.26 , the volume ratio is in the range of 3.6 and 4.0. According to Lazzaretto and Manente [75], these parameters would lead to an isentropic efficiency of a radial turbine between $84.0 \%$ and $86.5 \%$. 
A similar range for isentropic efficiency is obtained for the alternative considered working fluids. Exemplarily, the use of R227ea/R245fa shows isentropic turbine efficiencies between $83.0 \%$ and $86.0 \%$. Here, the size parameter varies in the range of 0.17 and 0.24 and the volume ratio is in the range of 4.5 and 7.6. Regarding the mixture butane/pentane, the turbine efficiency ranges between $84.0 \%$ and $86.75 \%$. This justifies the assumption of a constant isentropic efficiency of the turbine in this study.

\subsection{Heat Exchanger Design}

In Figure 12a the ratio between the heat transfer coefficient at condensation and evaporation and the ideal value $\alpha_{i d}$ is shown for the selected zeotropic mixtures isobutane/isopentane, propane/isobutane and R227ea/R245fa at a heat source temperature of $120{ }^{\circ} \mathrm{C}$. In general, the results show a slight reduction of the heat transfer characteristics in case of condensation. For isobutane/isopentane the most distinctive reduction with up to $18 \%$ is obtained. This is due to a low mass flux density and high enthalpy difference at condensation. In case of high mass flux densities, like for propane/isobutane and $\mathrm{R} 227 \mathrm{ea} / \mathrm{R} 245 \mathrm{fa}$, the reduction is less pronounced with maximal $8 \%$. The general behavior agrees with literature for experimental investigations of flow condensation of zeotropic mixtures [76,77]. In contrast, the reduction of pool boiling heat transfer coefficient is more significant. For isobutane/isopentane and propane/isobutane a minimum for $\alpha / \alpha_{i d}$ is obtained in case of an equimolar fraction. The reduction is $45 \%$ and $48 \%$. In case of R227ea /R245fa, the reduction is $37 \%$ at $40 \mathrm{~mol} \% \mathrm{R} 245 \mathrm{fa}$. In principle, high heat transfer coefficients are obtained for more volatile working fluids with higher process pressures and thus higher gaseous density.

Figure $12 \mathrm{~b}$ illustrates the total heat transfer surface of the ORC power plant, including internal heat exchanger, preheater, evaporator and condenser, depending on mixture composition at inlet temperature of the geothermal fluid of $120^{\circ} \mathrm{C}$. The local maxima for the total heat transfer surface correspond to the $U A$-parameter in Figure 9. The total heat exchange surface is mainly affected by the condenser dimensions. In this context, additionally to the reduction of the heat transfer coefficient at condensation, a low logarithmic mean temperature difference leads to high required heat transfer surfaces for efficient compositions.

In contrast, the logarithmic temperature difference for the evaporator and preheater differs only slightly for a variation of mixture composition (see Table 6). For isobutane/isopentane depending on mole fraction the logarithmic temperature difference of the preheater differs only up to $5 \%$ and in case of the evaporator $13 \%$. Differences in heat transfer surfaces of up to $47 \%$ for the preheater and up to $227 \%$ for the evaporator are due to a variation of thermodynamic characteristics as a function of mole fraction. More volatile working fluids show higher heat transfer surfaces for the preheater and for less volatile concentrations the evaporation heat transfer is dominant. As a consequence the sum of heat transfer surfaces concerning the heat input, preheater and evaporator differs only by $30 \%$ as a function of mixture composition. For the same mixture, a mole fraction of $90 \mathrm{~mol} \%$ isobutane leads to the highest power output. Due to the good glide match in the condenser the logarithmic mean temperature difference is $5.1 \mathrm{~K}$. As a result, the total heat transfer surface of $4218.1 \mathrm{~m}^{2}$ is relatively high. In case of an equimolar concentration, a logarithmic mean temperature difference of $8.1 \mathrm{~K}$ and a total heat transfer surface of $3,021.4 \mathrm{~m}^{2}$ are determined. The most efficient pure component isobutane leads to a logarithmic mean temperature difference of $7.2 \mathrm{~K}$ and a total heat transfer surface of $2,996.0 \mathrm{~m}^{2}$. 
(a)

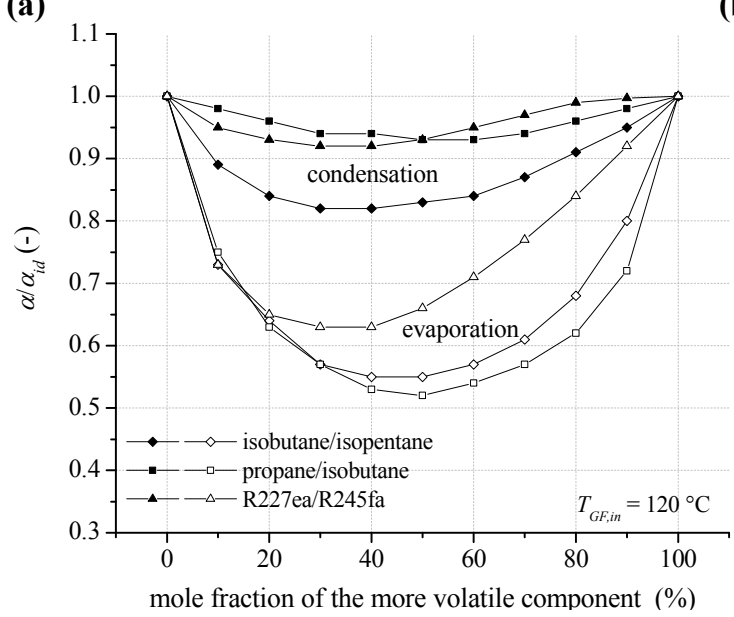

(b)

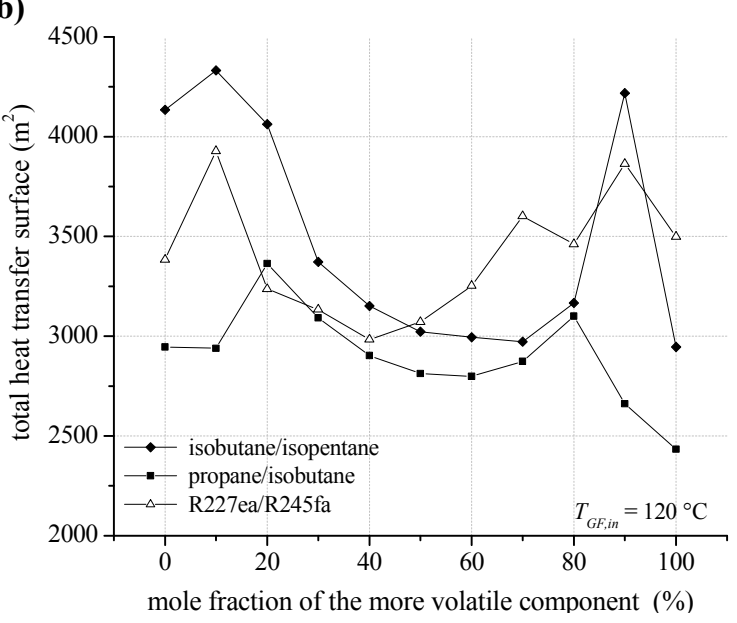

Figure 12. (a) Reduction of the heat transfer coefficient at condensation and evaporation (pool boiling) for zeotropic mixture depending on mixture composition (b) total heat transfer surface of the ORC power plant for a geothermal fluid temperature of $120^{\circ} \mathrm{C}$.

Table 6. Heat exchange surface, mean logarithmic temperature difference and transferred amount of thermal energy for each heat exchanger depending on mixture composition (isobutane/isopentane).

\begin{tabular}{cccccccccccc}
\hline Parameter & $\mathbf{0 / 1 0 0}$ & $\mathbf{1 0 / 9 0}$ & $\mathbf{2 0 / 8 0}$ & $\mathbf{3 0 / 7 0}$ & $\mathbf{4 0 / 6 0}$ & $\mathbf{5 0 / 5 0}$ & $\mathbf{6 0 / 4 0}$ & $\mathbf{7 0 / 3 0}$ & $\mathbf{8 0 / 2 0}$ & $\mathbf{9 0 / 1 0}$ & $\mathbf{1 0 0} / \mathbf{0}$ \\
\hline$A_{P H E}\left(\mathrm{~m}^{2}\right)$ & 280.6 & 272.2 & 301.4 & 294.5 & 302.1 & 312.4 & 329.4 & 342.4 & 366.1 & 390.4 & 411.3 \\
$\Delta T_{\log , P H E}(\mathrm{~K})$ & 13.5 & 13.9 & 13.4 & 13.2 & 13.3 & 13.4 & 13.2 & 13.5 & 13.4 & 13.6 & 13.9 \\
$\dot{Q}_{P H E}(\mathrm{MW})$ & 3.44 & 3.42 & 3.38 & 3.48 & 3.56 & 3.68 & 3.81 & 4.01 & 4.22 & 4.53 & 4.85 \\
$A_{E V P}\left(\mathrm{~m}^{2}\right)$ & 495.8 & 518.3 & 600.2 & 622.5 & 614.8 & 587.7 & 537.0 & 473.1 & 404.5 & 330.4 & 274.3 \\
$\Delta T_{\log , E V P}(\mathrm{~K})$ & 19.2 & 17.6 & 18.7 & 17.2 & 16.9 & 16.8 & 17.2 & 17.2 & 17.8 & 18.3 & 18.5 \\
$\dot{Q}_{E V P}(\mathrm{MW})$ & 12.02 & 11.55 & 13.53 & 12.56 & 12.54 & 12.50 & 12.72 & 12.39 & 12.48 & 12.14 & 11.39 \\
$A_{C O N D}\left(\mathrm{~m}^{2}\right)$ & 2638.5 & 3541.1 & 3160.9 & 2455.2 & 2234.6 & 2121.8 & 2128.3 & 2156.8 & 2396.0 & 2915.9 & 1911.0 \\
$\Delta T_{\log , C O N D}(\mathrm{~K})$ & 7.2 & 5.1 & 6.4 & 7.5 & 8.0 & 8.1 & 8.0 & 7.4 & 6.5 & 5.1 & 7.2 \\
$\dot{Q}_{C O N D}(\mathrm{MW})$ & 13.94 & 13.34 & 15.32 & 14.46 & 14.53 & 14.60 & 14.92 & 14.76 & 15.02 & 14.96 & 14.66 \\
$A_{I R}\left(\mathrm{~m}^{2}\right)$ & 719.5 & 917.8 & 568.3 & 448.5 & 388.0 & 359.7 & 353.2 & 374.7 & 442.4 & 581.4 & 349.43 \\
$\Delta T_{\log , I R}(\mathrm{~K})$ & 6.5 & 7.2 & 10.3 & 12.6 & 13.7 & 13.9 & 13.3 & 11.9 & 9.5 & 6.6 & 5.9 \\
$\dot{Q}_{I R}(\mathrm{MW})$ & 0.94 & 1.36 & 1.29 & 1.29 & 1.25 & 1.22 & 1.17 & 1.14 & 1.11 & 1040.3 & 0.60 \\
$A_{\text {total }}\left(\mathrm{m}^{2}\right)$ & 4134.3 & 4331.6 & 4062.5 & 3372.2 & 3151.5 & 3021.9 & 2994.7 & 2972.3 & 3166.7 & 4218.1 & 2946.0 \\
$P_{T}(\mathrm{~kW})$ & 1520.7 & 1623.0 & 1587.7 & 1581.3 & 1583.5 & 1598.3 & 1623.1 & 1659.0 & 1704.0 & 1755.3 & 1631.5 \\
$P_{P}(\mathrm{~kW})$ & 27.8 & 34.2 & 35.6 & 42.3 & 47.6 & 53.4 & 59.1 & 66.9 & 74.5 & 84.7 & 94.6 \\
\hline
\end{tabular}

In case of a heat source temperature of $160{ }^{\circ} \mathrm{C}$, the reduction of heat transfer coefficient at condensation and evaporation depending on mixture composition for propane/isobutane and $\mathrm{R} 227 \mathrm{ea} / \mathrm{R} 245 \mathrm{fa}$ is shown in Figure 13a. Compared to a heat source temperature of $120{ }^{\circ} \mathrm{C}$, relevant parameters regarding condensation heat transfer like $R e_{g}$, differ only slightly. This is due to the assumption of a constant flow velocity in the pipes. In addition, $\operatorname{Prl}$ or $\operatorname{Prg}_{g}$ show only a low dependence on the increased process pressure. As a result, the reduction of condensation heat transfer coefficients is almost identical compared to the geothermal inlet temperature of $120^{\circ} \mathrm{C}$. Regarding the evaporation heat transfer, a more pronounced reduction for fluid mixtures can be observed. In case of an equimolar 
concentration for propane/isobutane, a reduction of $54 \%$ is calculated. Considering the mixture $\mathrm{R} 227 \mathrm{ea} / \mathrm{R} 245 \mathrm{fa}$ the maximal reduction is $43 \%$. Again, not mole fractions with the most evident reduction of heat transfer characteristics lead to the highest heat transfer surface (see Figure 13b). High total heat transfer surfaces for propane/isobutane and R227ea/R245fa occur for the most efficient mixture compositions. For these concentrations the ORC leads to a minimal reinjection temperature for the geothermal fluid and, therefore, a maximum for heat input to the ORC is obtained. Exemplarily, for the equimolar mixture R227ea/R245fa a higher amount of $29.0 \%$ thermal energy is transferred to the ORC compared to pure R245fa. As a consequence and taken into account the reduction of heat transfer characteristics, a $66.5 \%$ higher total heat transfer surface results. Local maxima for the total heat transfer surface can be observed for mole fractions, which lead to a good match of the temperature profiles in the condenser. In this context, 90 mol\% R227ea could be mentioned exemplarily.

(a)

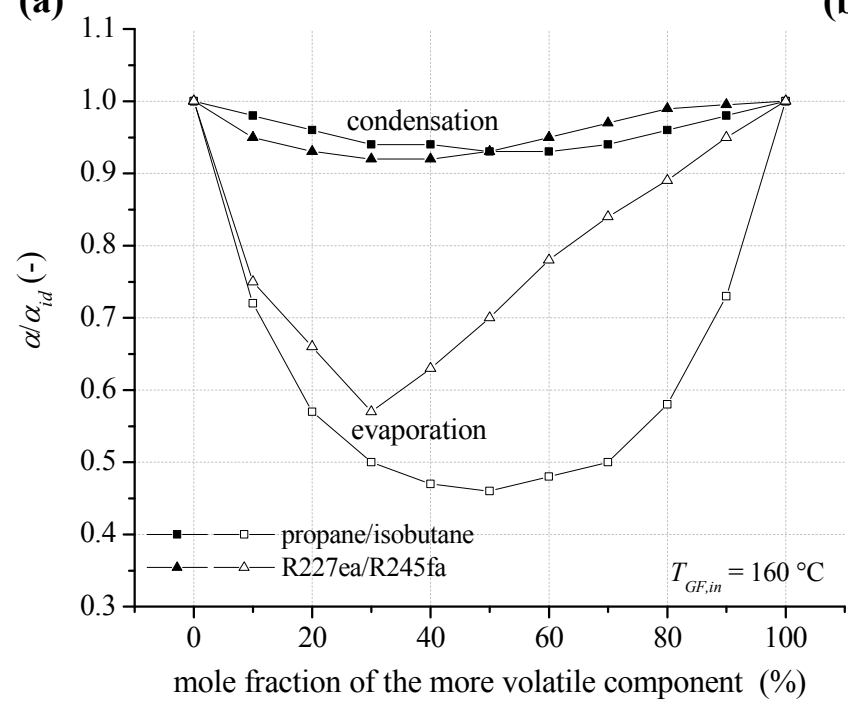

(b)

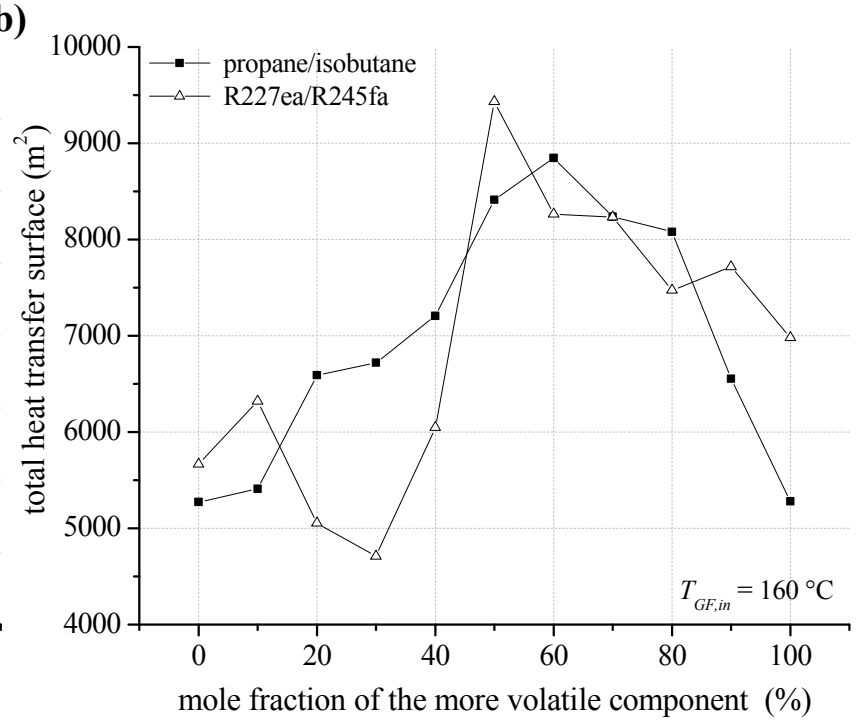

Figure 13. (a) Reduction of the heat transfer coefficient at condensation and evaporation (pool boiling) for zeotropic mixtures depending on composition; (b) total heat transfer surface of the ORC power plant for a geothermal fluid temperature of $160{ }^{\circ} \mathrm{C}$.

\subsection{Economic Parameters}

In the case of a heat source temperature of $120{ }^{\circ} \mathrm{C}, S I C$ for the ORC module depending on mole fraction of the considered fluid mixtures are shown in Figure 14a.

The total capital investment for an ORC system is determined according to Equation (15). In general, $P E C$ are dominated by costs for heat exchangers. In case of isobutane as a working fluid, $57.0 \%$ of the $P E C$ are costs for the preheater, evaporator, condenser and internal heat exchanger. A detailed overview for the $P E C$ of the major components depending on mixture composition of isobutane/isopentane is listed in Table 7. For the considered pure media and fluid mixtures, the heat exchanger costs in relation to total $P E C$ are in the range of $54.1 \%$ and $59.8 \%$. Therefore, working fluids showing a high total heat transfer surface lead to high SIC. For the examined heat source temperature of $120{ }^{\circ} \mathrm{C}$, SIC range between $4,882 € / \mathrm{kW}$ for isobutane/isopentane $(90 / 10)$ and $3,076 € / \mathrm{kW}$ in case of pure propane. The resulting costs for electricity generation $(E G C)$ are shown in Figure 14b. Due to high drilling costs concerning the exploration of a geothermal resource, high SIC could be overcompensated by an efficient ORC module. 
In case of the mixture isobutane/isopentane, a mole fraction of $90 \%$ isobutane leads to $E G C$ of $148.4 € / \mathrm{MWh}$. Compared to pure isobutane (153.8 €/MWh), $14 \%$ higher SIC could be considerably overcompensated. Also, in case of the mixture propane/isobutane higher SIC for a mole concentration of $80 \%$ propane are overcompensated compared to propane. However, R227ea leads to the lowest $E G C$ with $138.6 € / \mathrm{MWh}$.

(a)

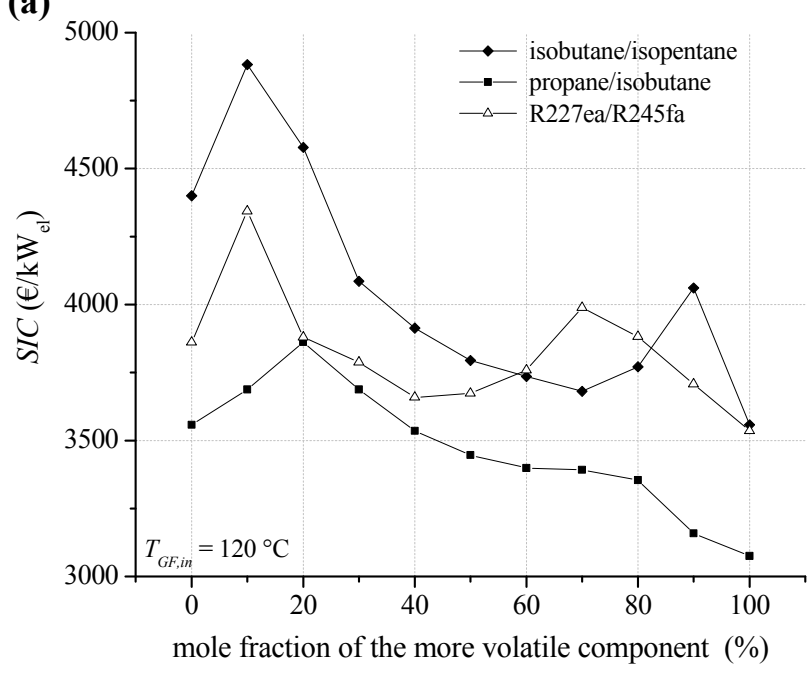

(b)

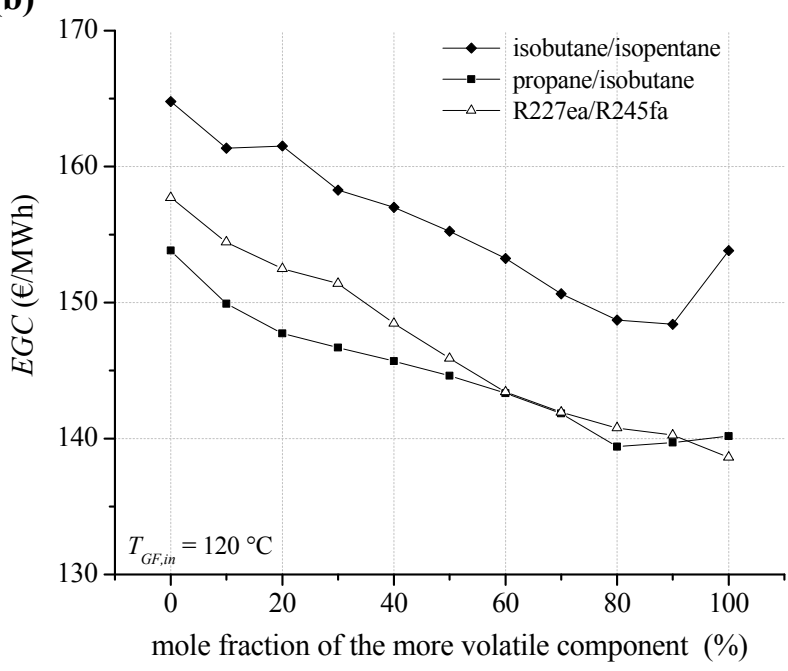

Figure 14. (a) Specific investment costs for the ORC power plant depending on mixture composition for a geothermal fluid temperature of $120^{\circ} \mathrm{C}$; (b) electricity generation costs.

Table 7. $P E C$ for the major components depending on mixture composition (isobutane/isopentane) at a geothermal fluid temperature of $120^{\circ} \mathrm{C}$.

\begin{tabular}{cccccccccccc}
\hline Parameter & $\mathbf{0 / 1 0 0}$ & $\mathbf{1 0 / 9 0}$ & $\mathbf{2 0 / 8 0}$ & $\mathbf{3 0 / 7 0}$ & $\mathbf{4 0 / 6 0}$ & $\mathbf{5 0 / 5 0}$ & $\mathbf{6 0 / 4 0}$ & $\mathbf{7 0 / 3 0}$ & $\mathbf{8 0 / 2 0}$ & $\mathbf{9 0 / 1 0}$ & $\mathbf{1 0 0} / \mathbf{0}$ \\
\hline$C_{I R}(\mathrm{k} €)$ & 115.9 & 148.0 & 92.9 & 75.6 & 67.1 & 63.2 & 62.3 & 65.3 & 74.7 & 94.9 & 61.8 \\
$C_{P H E}(\mathrm{k} €)$ & 52.6 & 51.5 & 55.3 & 54.4 & 55.4 & 56.8 & 59.1 & 60.9 & 64.1 & 67.5 & 70.4 \\
$C_{E V P}(\mathrm{k} €)$ & 82.3 & 85.6 & 97.7 & 101.0 & 99.9 & 95.8 & 88.3 & 79.1 & 69.4 & 59.3 & 51.7 \\
$C_{K}(\mathrm{k} €)$ & 427.3 & 573.5 & 511.9 & 397.7 & 361.9 & 343.6 & 344.7 & 349.3 & 388.1 & 472.3 & 309.5 \\
$C_{T}(\mathrm{k} €)$ & 354.0 & 360.9 & 358.3 & 357.4 & 357.2 & 357.8 & 359.2 & 361.1 & 363.6 & 366.3 & 357.2 \\
$C_{\text {Pump }}(\mathrm{k} €)$ & 7.1 & 7.9 & 8.0 & 8.8 & 9.4 & 10.1 & 10.7 & 11.6 & 12.4 & 13.4 & 14.4 \\
$C_{\text {total,ORC }}(\mathrm{k} €)$ & 6568.4 & 7756.9 & 7105.4 & 6288.0 & 6010.2 & 5861.3 & 5841.9 & 5860.3 & 6145.1 & 6785.2 & 5467.5 \\
\hline
\end{tabular}

Regarding a heat source temperature of $160^{\circ} \mathrm{C}, S I C$ and $E G C$ are illustrated in Figure 15a,b. Compared to lower heat source temperatures, the level and the bandwidth of SIC are decreased. Compared to geothermal inlet temperature of $120^{\circ} \mathrm{C}$, the percentage of heat exchanger costs is even increased. For the considered working fluids $62.3 \%$ to $77.1 \%$ of the total $P E C$ are related to heat exchangers. For propane/isobutane SIC range between 2,322 and $2,990 € / \mathrm{kW}$, in case of R227ea/R245fa between $2,407 € / \mathrm{kW}$ and 3,147€/kW. Considering $E G C$, fluid mixtures as ORC working fluids lead to a significant improvement of economic conditions for geothermal power generation. Compared to the most cost-efficient pure component R245fa, a decrease of $10.0 \%$ for $E G C$ is determined in case of $\mathrm{R} 227 \mathrm{ea} / \mathrm{R} 245 \mathrm{fa}(60 / 40)$. The lowest $E G C$ of $68.4 € / \mathrm{MWh}$ are obtained for propane/isobutane. A mole fraction of $60 \%$ isobutane leads to a reduction of $E G C$ of $4.0 \%$ compared to propane. In general, the obtained SIC are in a good agreement to the mentioned investigations [40-43]. 
(a)

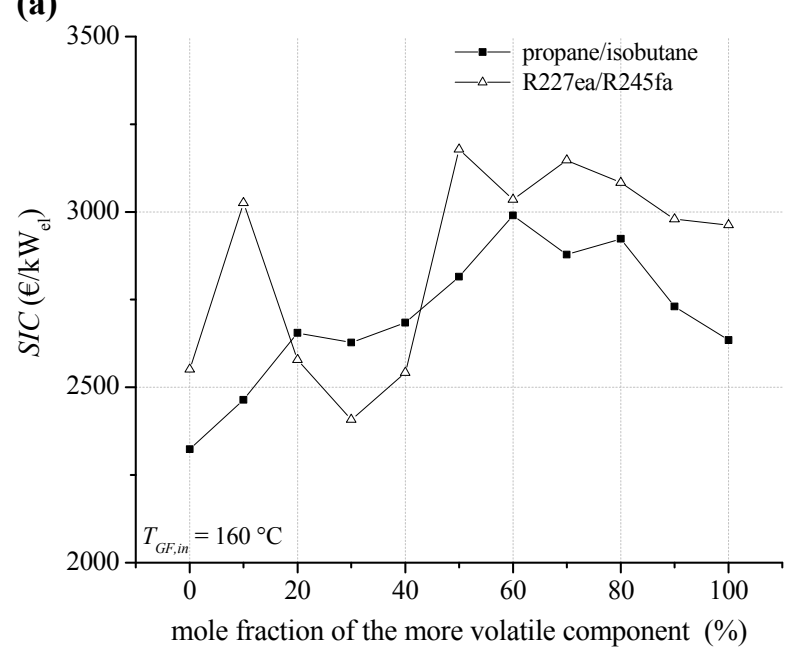

(b)

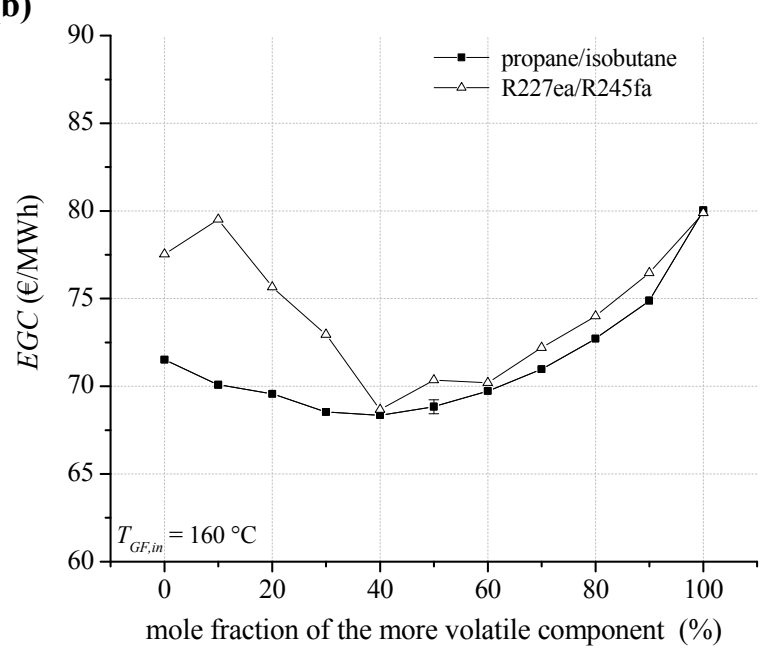

Figure 15. (a) Specific investment costs for the ORC power plant depending on mixture composition (b) electricity generation costs for a geothermal fluid temperature of $160{ }^{\circ} \mathrm{C}$.

In the context of the uncertainties of fluid properties, a sensitivity analysis is conducted for propane/isobutane (50/50). Based on the results of Section 3.2, where a maximal mean deviation of $4.7 \%$ is obtained for VLE-data of R134a/R245fa, the relevant fluid properties for heat exchanger design like density, heat capacity or viscosity are varied within a range of $-5 \%$ and $+5 \%$. In case of lower values $(-5 \%)$ an increase of the total heat transfer surface of 3.4\% results. This leads to a rise of SIC by $2.4 \%$ and finally EGC increase by $0.9 \%$ to $69.4 € / \mathrm{MWh}$. For $5 \%$ higher fluid properties, a reduction of $E G C$ by $0.8 \%$ results.

For further work, the implementation of a turbine model and pressure loss models for the heat exchangers would lead to a more comprehensive analysis. In addition, advanced heat exchanger design and alternative cost estimations models could be investigated. Furthermore, the adaption of the described methodology to alternative heat sources seems to be interesting due to differing temperature levels and exploitation costs. Finally, a validation and adaption of the considered heat transfer correlations for potential ORC working fluids would reduce additional uncertainties in heat exchanger design. In analogy, the measurement of fluid properties, especially for fluid mixtures, could lead to a more reliable heat exchanger design.

\section{Conclusions}

We evaluate zeotropic mixtures and pure components as potential working fluids for geothermal ORCs under thermo-economic criteria. The second law analysis shows an efficiency increase of up to $20.6 \%$ for zeotropic mixtures compared to the most efficient pure working fluid. For temperatures of the geothermal fluid up to $120{ }^{\circ} \mathrm{C}$, isobutane/isopentane, propane/isobutane and R134a/R236fa lead to high exergetic efficiencies. In the case of higher temperatures, next to isobutane/isopentane and propane/isobutane also R227ea/R245fa and R236fa/R245fa are favourable. Regarding pure fluids, a shift of the pinch point leads to a significant increase in efficiency for a certain temperature range of the heat source. For temperatures below $140^{\circ} \mathrm{C}$, this effect can be observed for R134a, R227ea and propane. For higher temperatures, R236fa and isobutane show this characteristic, too. In this context, R227ea leads to the highest second law efficiency of all considered working fluids for a geothermal fluid 
temperature of $130{ }^{\circ} \mathrm{C}$. Otherwise zeotropic mixtures allow an efficiency increase of minimal 5.4\% compared to pure working fluids.

The heat exchanger design and the economic analysis are performed for case studies at heat source temperatures of $120^{\circ} \mathrm{C}$ and $160{ }^{\circ} \mathrm{C}$ considering the most efficient mixtures and their pure components as working fluids. The calculation of the heat transfer coefficient at phase change shows significant reductions for mixtures compared to pure fluids due to an additional mass transfer. In the case of flow condensation, a reduction of up to $18 \%$ is observed for isobutane/isopentane. For flow boiling, the reduction is considerably pronounced. Exemplarily, the mixture propane/isobutane shows up to $48 \%$ lower heat transfer coefficients compared to the ideal value. In addition, the logarithmic temperature difference is low for mixture compositions, which leads to a good glide match of ORC and heat sink or source in the condenser and evaporator. Therefore, the most efficient mixture compositions lead to the highest heat transfer surfaces.

As a consequence, the economic analysis shows high SIC for fluid mixtures. Considering propane/isobutane for a geothermal temperature of $120^{\circ} \mathrm{C}$, SIC range between $3,076 € / \mathrm{kW}$ (propane) and $4,882 € / \mathrm{kW}(20 / 80)$. In the case of a heat source temperature of $160{ }^{\circ} \mathrm{C}$, the lowest $S I C$ are obtained for isobutane $(2,322 € / \mathrm{kW})$. For the mixture compositions, SIC are up to $2,990 € / \mathrm{kW}(60 / 40)$. However, our results indicate that higher specific investment costs for efficient systems are overcompensated due to the increased power output and annual amount of generated electricity. In general, a decrease of electricity generation costs is observed for the use of zeotropic mixtures as working fluids compared to pure fluids. For a temperature of geothermal fluid of $160{ }^{\circ} \mathrm{C}$, mixtures lead to a reduction of $E G C$ between $4.0 \%$ (propane/isobutane) and $10.0 \%$ (R227ea/R245fa) compared to the most cost-efficient pure component. Only for heat source temperatures of $120{ }^{\circ} \mathrm{C}$, pure R227ea in conjunction with a shift of pinch point leads with $138.6 € / \mathrm{MWh}$ to the lowest costs for electricity generation. Alternatively isobutane/isopentane (90/10) and isobutane are cost-efficient working fluids. However, they show $7.1 \%$ and $11.0 \%$ higher EGC compared to R227ea. In general, the differences for economic parameters mainly arise from heat exchanger dimensions. Thereby, process parameters and fluid properties have a significant influence on heat transfer characteristics. Determined uncertainties for fluid properties of about 5\% mainly affect the prediction of heat transfer characteristics. In this context, an increase of heat transfer surfaces of maximal 3.9\% is obtained. However, the calculation of $E G C$ is not influenced significantly by these uncertainties; the resulting increase is below $1.0 \%$.

In summary, we show that $E G C$ for geothermal ORCs can be decreased by using zeotropic mixtures as working fluids. Additional costs for the heat exchange equipment are generally overcompensated by an increase of power output. Consequently, zeotropic mixtures as ORC working fluids built a valuable approach for low-temperature applications, such as geothermal or waste heat recovery.

\section{Acknowledgments}

The work was partially funded by the Deutsche Forschungsgemeinschaft (DFG) with project No. BR 1713/12. The authors gratefully acknowledge this support. 


\section{Author Contributions}

All authors contributed to this work. Florian Heberle is the main author of this work. The whole project was supervised by Dieter Brüggemann.

\section{Conflicts of Interest}

The authors declare no conflict of interest.

\section{References}

1. DiPippo, R. Geothermal Power Plants; Elsevier Science: Oxford, UK, 2005.

2. Zarrouk, S.J.; Moon, H. Efficiency of geothermal power plants: A worldwide review. Geothermics 2014, 51, 142-153.

3. Invernizzi, C.; Bombarda, P. Thermodynamic performance of selected HCFS for geothermal applications. Energy 1997, 22, 887-895.

4. Madhawa Hettiarachchi, H.D.; Golubovic, M.; Worek, W.M.; Ikegami, Y. Optimum design criteria for an Organic Rankine Cycle using low-temperature geothermal heat sources. Energy 2007, 32, 1698-1706.

5. Saleh, B.; Koglbauer, G.; Wendland, M.; Fischer, J. Working fluids for low-temperature organic Rankine cycles. Energy 2007, 32, 1210-1221.

6. Hung, T.C.; Wang, S.K.; Kuo, C.H.; Pei, B.S.; Tsai, K.F. A study of organic working fluids on system efficiency of an ORC using low-grade energy sources. Energy 2010, 35, 1403-1411.

7. Heberle, F.; Brüggemann, D. Exergy based fluid selection for a geothermal Organic Rankine Cycle for combined heat and power generation. Appl. Therm. Eng. 2010, 30, 1326-1332.

8. Guo, T.; Wang, H.X.; Zhang, S.J. Selection of working fluids for a novel low-temperature geothermally-powered ORC based cogeneration system. Energy Convers. Mang. 2011, 52, 2384-2391.

9. Angelino, G.; Colonna di Paliano, P. Multicomponent working fluids for Organic Rankine Cycles (ORCs). Energy 1998, 23, 449-463.

10. Angelino, G.; Colonna di Paliano, P. Air cooled siloxane bottoming cycle for molten carbonate fuel cells. In Proceedings of 2000 Fuel Cell Seminar, Portland, OR, USA, 30 October-2 November 2000; pp. 667-670.

11. Iqbal, K.Z.; Fish, L.W.; Starling, K.E. Advantages of using mixtures as working fluids in geothermal binary cycles. Proc. Okla. Acad. Sci. 1976, 56, 110-113.

12. Demuth, O.J. Analyses of mixed hydrocarbon binary thermodynamic cycles for moderate temperature geothermal resources. In Proceedings of the IECEC Conference, Atlanta, GA, USA, 9 August 1981.

13. Bliem, C.J. Preliminary Performance Estimates of Binary Geothermal Using Mixed-Halocarbon Working Fluids; U.S. Department of Energy: Idaho Falls, NJ, USA, 1986; Contract No. DE-AC07-76IDO1570.

14. Borsukiewicz-Gozdur, A.; Nowak, W. Comparative analysis of natural and synthetic refrigerants in application to low temperature Clausius-Rankine cycle. Energy 2007, 32, 344-352. 
15. Wang, X.D.; Zhao, L. Analysis of zeotropic mixtures used in low-temperature solar Rankine cycles for power generation. Sol. Energy 2009, 83, 605-613.

16. Wang, J.L.; Zhao, L.; Wang, X.D. A comparative study of pure and zeotropic mixtures in low-temperature solar Rankine cycle. Appl. Energy 2010, 87, 3366-3373.

17. Chen, H.; Goswami, D.Y.; Rahman, M.M.; Stefanakos, E.K. A supercritical Rankine cycle using zeotropic mixture working fluids for the conversion of low-grade heat into power. Energy 2011, $36,549-555$.

18. Heberle, F.; Preißinger, M.; Brüggemann, D. Zeotropic mixtures as working fluids in Organic Rankine Cycles for low-enthalpy geothermal resources. Renew. Energy 2012, 37, 364-370.

19. Chys, M.; van den Broek, M.; Vanslambrouck, B.; de Paepe, M. Potential of zeotropic mixtures as working fluids in organic Rankine cycles. Energy 2012, 44, 623-632.

20. Baik, Y.J.; Kim, M.; Chang, K.C.; Lee, Y.S.; Yoon, H.K. Power enhancement potential of a mixture transcritical cycle for a low-temperature geothermal power generation. Energy 2012, 47, 70-76.

21. Preißinger, M.; Heberle, F.; Brüggemann, D. Advanced Organic Rankine Cycle for geothermal application. Int. J. Low-Carbon Technol. 2012, 8, 62-68.

22. Garg, P.; Kumar, P.; Srinivasan, K.; Dutta, P. Evaluation of isopentane, R-245fa and their mixtures as working fluids for organic Rankine cycles. Appl. Therm. Eng. 2013, 51, 292-300.

23. Yang, K.; Zhang, H.; Wang, Z.; Zhang, J.; Yang, F.; Wang, E.; Yao, B. Study of zeotropic mixtures of ORC (organic Rankine cycle) under engine various operating conditions. Energy 2013, 58, 494-510.

24. Aghahosseini, S.; Dincer, I. Comparative performance analysis of low-temperature Organic Rankine Cycle (ORC) using pure and zeotropic working fluids. Appl. Therm. Eng. 2013, 54, 35-42.

25. Zhao, L.; Bao, J. Thermodynamic analysis of organic Rankine cycle using zeotropic mixtures. Appl. Energy 2014, 130, 748-756.

26. Shu, G.; Gao, Y.; Tian, H.; Wei, H.; Liang, X. Study of mixtures based on hydrocarbons used in ORC (Organic Rankine Cycle) for engine waste heat recovery. Energy 2014, 74, 428-438.

27. Radulovic, J.; Beleno Castaneda, N.I. On the potential of zeotropic mixtures in supercritical ORC powered by geothermal energy source. Energy Convers. Manag. 2014, 88, 365-371.

28. Andreasen, J.G.; Larsen, U.; Knudsen, T.; Pierobon, L.; Haglind, F. Selection and optimization of pure and mixed working fluids for low grade heat utilization using organic rankine cycles. Energy 2014, 73, 204-213.

29. Lecompte, S.; Ameel, B.; Ziviani, D.; van Den Broek, M.; de Paepe, M. Exergy analysis of zeotropic mixtures as working fluids in Organic Rankine Cycles. Energy Convers. Manag. 2014, $85,727-739$.

30. Dong, B.; Xu, G.; Cai, Y.; Li, H. Analysis of zeotropic mixtures used in high-temperature Organic Rankine cycle. Energy Convers. Manag. 2014, 84, 253-260.

31. Weith, T.; Heberle, F.; Brüggemann, D. Performance of siloxane mixtures in a high-temperature Organic Rankine Cycle considering the heat transfer characteristics during evaporation. Energies 2014, 7, 5548-5565.

32. Heberle, F.; Preißinger, M.; Brüggemann, D. Thermoeconomic evaluation of combined heat and power generation for geothermal applications. In Proceedings of the World Renewable Energy Congress, Linköping, Sweden, 8-13 May 2011; pp. 1305-1313. 
33. Heberle, F.; Bassermann, P.; Preissinger, M.; Brüggemann, D. Exergoeconomic optimization of an Organic Rankine Cycle for low-temperature geothermal heat sources. Int. J. Thermodyn. 2012, $15,119-126$.

34. Al-Sulaiman, F.A.; Dincer, I.; Hamdullahpur, F. Thermoeconomic optimization of three trigeneration systems using organic Rankine cycles: Part I-Formulations. Energy Convers. Manag. 2013, 69, 199-208.

35. Algieri, A.; Morrone, P. Techno-economic analysis of biomass-fired ORC systems for single-family Combined Heat and Power (CHP) applications. Energy Proced. 2014, 45, 1285-1294.

36. Calise, F.; Capuozzo, C.; Carotenuto, A.; Vanoli, L. Thermoeconomic analysis and off-design performance of an Organic Rankine Cycle powered by medium-temperature heat sources. Sol. Energy 2014, 103, 595-609.

37. Ahmadi, P.; Dincer, I.; Rosen, M.A. Thermoeconomic multi-objective optimization of a novel biomass-based integrated energy system. Energy 2014, 68, 958-970.

38. Heberle, F.; Brüggemann, D. Thermoeconomic analysis of hybrid power plant concepts for geothermal combined heat and power generation. Energies 2014, 7, 4482-4497.

39. Quoilin, S.; Declaye, S.; Tchanche, B.F.; Lemort, V. Thermo-economic optimization of waste heat recovery Organic Rankine Cycles. Appl. Therm. Eng. 2011, 31, 2885-2893.

40. Imran, M.; Park, B.S.; Kim, H.J.; Lee, D.H.; Usman, M.; Heo, M. Thermo-economic optimization of Regenerative Organic Rankine Cycle for waste heat recovery applications. Energy Convers. Manag. 2014, 87, 107-118.

41. Quoilin, S.; Broek, M.V.D.; Declaye, S.; Dewallef, P.; Lemort, V. Techno-economic survey of Organic Rankine Cycle (ORC) systems. Renew. Sustain. Energy Rev. 2013, 22, 168-186.

42. Astolfi, M.; Romano, M.C.; Bombarda, P.; Macchi, E. Binary ORC (Organic Rankine Cycles) power plants for the exploitation of medium-low temperature geothermal sources-Part B: Techno-economic optimization. Energy 2014, 66, 435-446.

43. Tempesti, D.; Fiaschi, D. Thermo-economic assessment of a micro CHP system fuelled by geothermal and solar energy. Energy 2013, 58, 45-51.

44. VDI Heat Atlas; Springer-Verlag: Berlin/Heidelberg, Germany, 2010.

45. Lemmon, E.W.; Huber, M.L.; McLinden, M.O. NIST Standard Reference Database 23-Version 8.0. Physical and Chemical Properties Division; National Institute of Standards and Technology: Boulder, CO, USA, 2002.

46. Woudstra, N.; van der Stelt, T.P. Cycle-Tempo: A Program for the Thermodynamic Analysis and Optimization of Systems for the Production of Electricity, Heat and Refrigeration; Energy Technology Section, Delft University of Technology: Delft, The Netherlands, 2002.

47. Sieder, E.N.; Tate, G.E. Heat transfer and pressure drop of liquids in tubes. Ind. Eng. Chem. 1936, $28,1429-1435$.

48. Kern, D.Q. Process Heat Transfer; McGraw-Hill: New York, NY, USA, 1950.

49. Stephan, K.; Abdelsalam, M. Heat-transfer correlations for natural convection boiling. Int. J. Heat Mass Transf. 1980, 23, 73-87.

50. Heberle, F.; Brüggemann, D. Pool boiling heat transfer coefficients of R245fa, R365mfc and their mixtures. In Proceedings of the 8th World Conference on Experimental Heat Transfer, Fluid Mechanics, and Thermodynamics, Lisbon, Portugal, 16-20 June 2013. 
51. Schlünder, E.U. Heat transfer in nucleate boiling of mixtures. Int. Chem. Eng. 1983, 23, 589-599.

52. Shah, M.M. A general correlation for heat transfer during film condensation inside pipes. Int. J. Heat Mass Transf. 1979, 22, 547-556.

53. Silver, R.S. An approach to a general theory of surface condensers. Proc. Inst. Mech. Eng. 1963, 178, 339-357.

54. Bell, J.; Ghaly, A. An approximate generalized design method for multicomponent/partial condensers. AIChE Symp. Ser. Heat Transf. 1973, 69, 72-79.

55. Turton, R.; Bailie, R.C.; Whiting, W.B. Analysis, Synthesis and Design of Chemical Processes, 2nd ed.; Prentice Hall: Old Tappan, NJ, USA, 2003.

56. Bejan, A.; Tsatsaronis, G.; Moran, M. Thermal Design \& Optimization; John Wiley \& Sons: New York, NY, USA, 1996.

57. Frick, S.; Kaltschmitt, M.; Schröder, G. Life cycle assessment of geothermal binary power plants using enhanced low-temperature reservoirs. Energy 2010, 25, 2281-2294.

58. Lemmon, E.W.; Jacobsen, R.T. Equations of state for mixtures of R-32, R-125, R-134a, R-143a, and R-152a. J. Phys. Chem. Ref. Data 2004, 33, 593-620.

59. Kunz, O.; Klimeck, R.; Wagner, W.; Jaeschke, M. The GERG-2004 Wide-Range Equation of State for Natural Gases and Other Mixtures-GERG Technical Monograph; VDI-Fortschritts-Bericht: Düsseldorf, Germany, 2007.

60. Tillner-Roth, R.; Baehr, H.D. An international standard formulation of the thermodynamic properties of 1,1,1,2-tetrafluoroethane (HFC-134a) for temperatures from $170 \mathrm{~K}$ to $455 \mathrm{~K}$ at pressures up to $70 \mathrm{MPa}$. J. Phys. Chem. Ref. Data 1994, 23, 657-729.

61. Buecker, D.; Wagner, W. Reference equations of state for the thermodynamic properties of fluid phase $n$-butane and isobutane. J. Phys. Chem. Ref. Data 2006, 35, 929-1019.

62. Lemmon, E.W.; Span, R. Short fundamental equations of state for 20 industrial fluids. J. Chem. Eng. Data 2006, 51, 785-850.

63. Span, R.; Wagner, W. Equations of state for technical applications. II. Results for nonpolar fluids. Int. J. Thermophys. 2003, 24, 41-109.

64. Valtz, A.; Gicquel, L.; Coquelet, C.; Richon, D. Vapor-liquid equilibrium data for the 1,1,1,2 tetrafluoroethane (R134a) + dimethyl ether (DME) system at temperatures from 293.18 to 358.15 K and pressures up to about $3 \mathrm{MPa}$. Fluid Phase Equilib. 2005, 230, 184-191.

65. Warowny, W. Phase behavior of the acetonitrile + butane system at temperatures from $311.40 \mathrm{~K}$ to 436.82 K. J. Chem. Eng. Data 1996, 41, 689-697.

66. Abdulagatov, I.M.; Rasulov, S.M. Viscosity of $n$-pentane, $n$-heptane and their mixtures within the temperature range from $298 \mathrm{~K}$ up to critical points at the saturation vapor pressure. Ber. Bunsenges. Phys. Chem. 1996, 100, 148-154.

67. Feng, X.; Xu, X.; Lin, H.; Duan, Y. Vapor pressures of 1,1,1,2,3,3,3-heptafluoropropane, 1,1,1,3,3,3-hexafluoropropane and 1,1,1,3,3-pentafluoropropane. Fluid Phase Equilib. 2010, 290, $127-136$.

68. Calingaert, G.; Hitchcock, L.B. The application of the phase rule to the calculation of liquid and vapor compositions in binary systems. Deviations from Raoult's Law for hydrocarbon mixtures. J. Am. Chem. Soc. 1927, 49, 750-765. 
69. Lim, J.S.; Park, J.Y.; Kang, J.W.; Lee, B.G. Measurement of vapor-liquid equilibria for the binary systems of propane $+1,1,1,2$-tetrafluoroethane and 1,1,1-trifluoroethane + propane at various temperatures. Fluid Phase Equilib. 2006, 243, 57-63.

70. Bobbo, S.; Fedele, L.; Scattolini, M.; Camporese, R. Isothermal VLE measurements for the binary mixtures HFC-134a + HFC-245fa and HC-600a + HFC-245fa. Fluid Phase Equilib. 2001, 185, 255-264.

71. Bobbo, S.; Stryjek, R.; Elvassore, N.; Bertucco, A. A recirculation apparatus for vapor-liquid equilibrium measurements of refrigerants. Binary mixtures of R600a, R134a and R236fa. Fluid Phase Equilib. 1998, 150-151, 343-352.

72. Kleiber, M. Vapor-liquid equilibria of binary refrigerant mixtures containing propylene or R134a. Fluid Phase Equilib. 1994, 92, 149-194.

73. Kayukawa, Y.; Watanabe, K. PTx-measurements for gas-phase Pentafluoroethane + Propane mixtures by the Burnett method. J. Chem. Eng. Data 2001, 46, 1025-1030.

74. Angelino, G.; Gaia, M.; Macchi, E. A review of Italian activity in the field of Organic Rnkine Cycles. VDI-Berichte 1984, 539, 465-482.

75. Lazzaretto, A.; Manente, G. A new criterion to optimize ORC design performance using efficiency correlations for axial and radial turbines. Int. J. Thermodyn. 2014, 17, 173-181.

76. Smit, F.J.; Meyer, J.P. Condensation heat transfer coefficients of the zeotropic refrigerant mixture R-22/R-142b in smooth horizonal tubes. Int. J. Therm. Sci. 2002, 41, 625-630.

77. Shao, D.W.; Granryd, E. Experimental and theoretical study on flow condensation with non-azeotropic refrigerant mixtures of R32/R134a. Int. J. Refrig. 1998, 21, 230-246.

(C) 2015 by the authors; licensee MDPI, Basel, Switzerland. This article is an open access article distributed under the terms and conditions of the Creative Commons Attribution license (http://creativecommons.org/licenses/by/4.0/). 